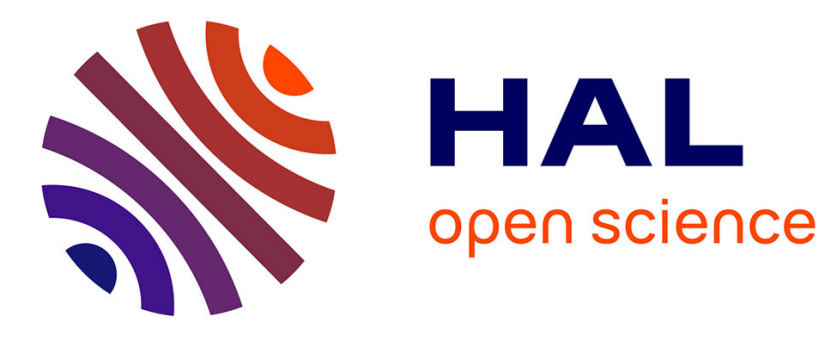

\title{
Results of POLDER in-flight calibration
}

Olivier Hagolle, Philippe Goloub, Pierre-Yves Deschamps, Hélène Cosnefroy, Xavier Briottet, Thierry Bailleul, Jean-Marc Nicolas, Frédéric Parol, B. Lafrance, Maurice Herman

\section{- To cite this version:}

Olivier Hagolle, Philippe Goloub, Pierre-Yves Deschamps, Hélène Cosnefroy, Xavier Briottet, et al.. Results of POLDER in-flight calibration. IEEE Transactions on Geoscience and Remote Sensing, 1999, 37 (3), pp.1550 - 1566. 10.1109/36.763266 . hal-00811201

\section{HAL Id: hal-00811201 https://hal.science/hal-00811201}

Submitted on 10 Apr 2013

HAL is a multi-disciplinary open access archive for the deposit and dissemination of scientific research documents, whether they are published or not. The documents may come from teaching and research institutions in France or abroad, or from public or private research centers.
L'archive ouverte pluridisciplinaire $\mathbf{H A L}$, est destinée au dépôt et à la diffusion de documents scientifiques de niveau recherche, publiés ou non, émanant des établissements d'enseignement et de recherche français ou étrangers, des laboratoires publics ou privés. 


\title{
Results of POLDER In-Flight Calibration
}

\author{
Olivier Hagolle, Philippe Goloub, Pierre-Yves Deschamps, Hélène Cosnefroy, Xavier Briottet, \\ Thierry Bailleul, Jean-Marc Nicolas, Frédéric Parol, Bruno Lafrance, and Maurice Herman
}

\begin{abstract}
POLDER is a CNES instrument on board NASDA's ADEOS polar orbiting satellite, which was successfully launched in August 1996. On October 30, 1996, POLDER entered its nominal acquisition phase and worked perfectly until ADEOS's early end of service on June 30, 1997. POLDER is a multispectral imaging radiometer/polarimeter designed to collect global and repetitive observations of the solar radiation reflected by the earth/atmosphere system, with a wide field of view $(2400 \mathrm{~km})$ and a moderate geometric resolution $(6 \mathrm{~km})$. The instrument concept is based on telecentric optics, on a rotating wheel carrying 15 spectral filters and polarizers, and on a bidimensional charge coupled device (CCD) detector array. In addition to the classical measurement and mapping characteristics of a narrow-band imaging radiometer, POLDER has a unique ability to measure polarized reflectances using three polarizers (for three of its eight spectral bands, 443 to $910 \mathrm{~nm}$ ) and to observe target reflectances from 13 different viewing directions during a single satellite pass.

One of POLDER's original features is that its in-flight radiometric calibration does not rely on any on-board device. Many calibration methods using well-characterized calibration targets have been developed to achieve a very high calibration accuracy. This paper presents the various methods implemented in the in-flight calibration plan and the results obtained during the instrument calibration phase: absolute calibration over molecular scattering, interband calibration over sunglint and clouds, multiangular calibration over deserts and clouds, intercalibration with Ocean Color and Temperature Scanner (OCTS), and water vapor channels calibration over sunglint using meteorological analysis. A brief description of the algorithm and of the performances of each method is given.
\end{abstract}

Index Terms-Atmosphere, calibration, in-flight, optical remote sensing, vicarious.

\section{ACRONYMS}

$\begin{array}{ll}\text { ADEOS } & \text { Advanced Earth Observing Satellite. } \\ \text { ATSR2 } & \text { Along Track Scanning Radiometer-2. } \\ \text { BRDF } & \text { Bidirectional reflectance distribution function. } \\ \text { ECMWF } & \begin{array}{l}\text { European Center for Mean-Range Weather } \\ \text { Forecast. }\end{array} \\ \text { ERS2 } & \text { European Remote-Sensing Satellite 2. } \\ \text { LUT } & \text { Look-up table. } \\ \text { MISR } & \text { Multiangle Imaging Spectro-Radiometer. }\end{array}$

Manuscript received April 16, 1998; revised January 25, 1999. The results presented in this paper were obtained using data from CNES's POLDER on board NASDA's ADEOS. The ECMWF meteorological data was provided by Meteo France.

O. Hagolle and B. Lafrance are with the Centre National d'Etudes Spatiales (CNES), 31055 Toulouse Cedex France (e-mail: Olivier.Hagolle@cnes.fr).

P. Goloub, P.-Y. Deschamps, T. Bailleul, J.-M. Nicolas, F. Parol, and M. Herman are with the Université des Sciences et Technologies de Lille, Laboratoire d'Optique Atmosphérique, Lille, France.

H. Cosnefroy and X. Briottet are with the Office National d'Etudes et Recherches Aerospatiales, Département d'Optique Théorique et Appliquée, Toulouse, France.

Publisher Item Identifier S 0196-2892(99)03569-X.
MODIS Moderate-Resolution Imaging Radiometer.

OCTS Ocean Color and Temperature Scanner.

POLDER Polarization and directionality of earth reflectances.

SeaWIFS Sea-Viewing Wide Field-of-View Sensor.

SPOT Satellite pour l'Observation de la Terre (earth observing satellite).

SOS Successive orders of scattering.

TOA Top of atmosphere.

\section{INTRODUCTION}

$\mathbf{R}$ ADIOMETRIC calibration accuracy is one of the major elements contributing to the quality of the measurements obtained with optical remote sensing instruments. This radiometric calibration can be obtained through preflight measurements in optical laboratories, but the accuracy of these measurements is not perfect (precise radiance calibration is a difficult subject, and extraterrestrial solar irradiance is not perfectly known). Moreover, the instruments are subject to degradation after launch because of the aging of the optics or of the outgassing which occurs when the instrument leaves the atmosphere. To cope with this problem, many spaceborne instruments are equipped with on-board calibration devices. SPOT satellites [22] have an inner lamp and an optical fiber system to observe the sun. Actually, the inner lamp is used only for multitemporal monitoring of the instrument sensitivity and for detector normalization. The solar observations are affected by a difficult preflight calibration of the system itself and by a slow degradation of the optical fibers. SPOT calibration relies now mainly on natural targets. OCTS on board ADEOS is also equipped with inner lamps and a solar observation system: but the OCTS calibration provided by these devices is not very accurate because of degradation of the lamps after the launch and of nonuniformity in the mirror which allows observation of the sun. These problems lead to the decision of using natural targets for OCTS calibration [26]. ATSR2 on board ERS2 is also equipped with a visible sunobserving calibration device which is operationally used but needs to be completed by multitemporal calibration over desert sites to correct a drift of the solar calibration signal [34]. Many future instruments have also based their calibration mainly on on-board devices, such as SeaWIFS, MODIS, and MISR onboard EOS AM-1, but are also developing vicarious methods in order to verify the on-board device [33].

The POLDER project team has decided to avoid the development of an on-board calibration system. Past experiences of on-board calibration devices in CNES with SPOT satellites have failed to provide accurate results, and vicarious 
TABLE I

Spectral Band Characteristics for the POLDER Instrument Aboard the ADEOS-1 Satellite. This Table Differs from the Figures Previously Published in [9], Which Were Based on Early Budgets

\begin{tabular}{c|c|c|c|c|c|c|c|c|c}
\hline POLDER band & 443 & 443 & 490 & 565 & 670 & 763 & 765 & 865 & 910 \\
\hline \begin{tabular}{c} 
Central Wavelength (nm) \\
\hline Band Width (nm)
\end{tabular} & 444.5 & 444,9 & 492.2 & 564.5 & 670.2 & 763.3 & 763.1 & 860.8 & 907.7 \\
\hline Polarization & Yes & No & No & No & Yes & No & No & Yes & No \\
\hline $\begin{array}{c}\text { Saturation level } \\
\text { (normalized radiance) }\end{array}$ & 1.1 & 0.97 & 0.75 & 0.48 & 1.1 & 1.1 & 1.1 & 1.1 & 1.1 \\
\hline
\end{tabular}

methods using natural targets were necessary to obtain the required absolute calibration. Moreover, the implementation of a calibration system in POLDER compact design would have been expensive and hazardous in case of failure, and it was difficult to build a device that could have covered the entire POLDER bidimensional field of view. To compensate for the lack of an on-board calibrating source, lots of effort has been invested in the development of a very stable instrument [1], in an exhaustive and accurate preflight calibration [3], and in the adaptation and enhancement of calibration methods over natural targets.

Such methods have been intensively used to calibrate AVHRR/NOAA or METEOSAT and have achieved good results [24], [36], [38] using natural targets such as molecular scattering over ocean for absolute calibration, high altitude clouds, or ocean sunglint for interband calibration and desert sites. The POLDER calibration plan adapts all these methods to make use of the multidirectional and polarization measurements of the instrument. New calibration methods have also been introduced to characterize the POLDER sensitivity to polarization [43].

\section{THE POLDER INSTRUMENT ON ADEOS}

The POLDER radiometer design consists of three principal components: a charge coupled device (CCD) matrix detector, a rotating wheel carrying the polarizers and spectral filters, and a wide field of view (FOV) telecentric optics [9], [21]. The optics has a focal length of $3.57 \mathrm{~mm}$, opening to $\mathrm{f} / 4.5$ with a maximum FOV of $114^{\circ}$.

The CCD sensor array is composed of $242 \times 274$ independent sensitive areas. The total array detection unit size is $6.5 \times 8.8 \mathrm{~mm}^{2}$, which corresponds to along-track and crosstrack field-of-view of $\pm 43^{\circ}$ and $\pm 51^{\circ}$, respectively, and to a diagonal FOV of $\pm 57^{\circ}$. The spectral sensitivity of the CCD array extends between 400 and $1050 \mathrm{~nm}$.

The rotating wheel, which rotates steadily with a period of $4.9 \mathrm{~s}$, carries the interference filters and polarizers that select the spectral band and polarization direction. It carries 16 slots, including an opaque filter to estimate the CCD detector dark current. The remaining 15 slots carry six unpolarized and nine polarized filters (three polarization directions for three different wavelengths). Thus, POLDER acquires measurements in nine bands, three of which are polarized. POLDER filters have been designed to avoid any spectral variation of the filters when passing from air to vacuum (filters are made with an ion-assisted deposition technology). This characteristic is the key for an accurate in-flight calibration, since the spectral sensitivity of the bands measured before launch is still reliable after launch.

\section{A. Spectral Bands}

POLDER has nine spectral bands ranging from 443 to 910 $\mathrm{nm}$. Two of these spectral bands are centered on molecular absorption bands: $763\left(\mathrm{O}_{2}\right)$ and $910\left(\mathrm{H}_{2} \mathrm{O}\right)$. The nine bands are defined by their central wavelength, spectral width, and polarization capability. The saturation levels are given in unit of normalized radiance, i.e., the maximum spectral radiance divided by the solar spectral irradiance at nadir and multiplied by $\pi$. The saturation level in reflectance is subsequently obtained by dividing the value given in Table I by $\cos \left(\theta_{s}\right)$, where $\theta_{s}$ is the solar zenith angle. Owing to the signal-tonoise requirements for ocean color measurements, the 443-nm channel had to be split into a polarized band (three filters: $443 \mathrm{P}$ ) and an unpolarized band (one filter: 443NP).

\section{B. Polarization Measurements}

For three of the nine spectral bands $(443,670$, and 865 $\mathrm{nm}$ ), a polarizer is added to the filters in order to assess the degree of linear polarization and the polarization direction. These parameters are derived by combining measurements in three channels with the same spectral filters but with the polarizer axes turned by steps of $60^{\circ}$. The three polarization measurements in a spectral band are successive and have a total time lag of $0.6 \mathrm{~s}$ between the first and the third (last) measurement. In order to compensate for spacecraft motion during the lag and to register the three measurements, a smallangle wedge prism is used in each polarizing assembly. As a consequence, the matrix image is translated in the focal plane to offset the satellite motion, and the three polarization measurements are collocated.

\section{Spatial Resolution}

The ground size or resolution of a POLDER-measured pixel from ADEOS is $6 \times 7 \mathrm{~km}^{2}$ at nadir. Due to the earth curvature, the pixel size depends slightly on the viewing angle, leading to an increase of $21 \%$ for an incidence angle of $60^{\circ}$.

\section{Data Acquisition}

The POLDER instrument is in imaging mode on the sunlit part of the ADEOS orbit only. Data acquisition starts when the solar zenith angle on the earth surface at the satellite 


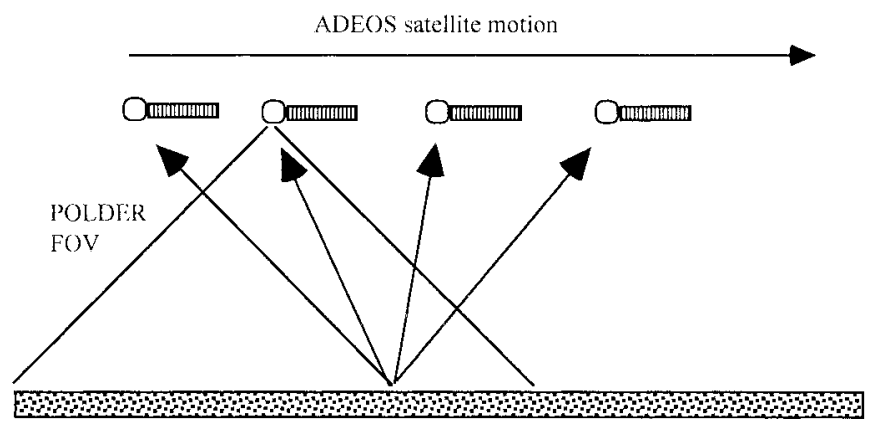

Fig. 1. POLDER multidirectional viewing principle. Owing to its bidimensional wide field of view, POLDER has the ability of looking at the same point on the ground from different viewing angles during a single orbit.

nadir is smaller than $75^{\circ}$ and stops, in the south, when it is larger than $75^{\circ}$. The 16 -filter sequence is repeated every 19.6 s. During this interval, a given point on the surface, initially at nadir viewing, moves by about $9^{\circ}$ relative to the satellite (Fig. 1). The point remains within the POLDER field of view. As the satellite passes over a target, about 12 (up to 14) directional radiance measurements (for each spectral band) are performed aiming at the point. Therefore, POLDER successive observations allow the measurement of the bidirectional reflectance properties of any target within the instrument swath.

ADEOS is on a sun synchronous orbit at an altitude of 797 $\mathrm{km}$. Thanks to POLDER's very wide field of view, each point on the earth is observed by POLDER every day, except near the equator where one point is only observed four days out of five. Combining all the viewing directions obtained during a one-week period, a very complete sampling of any target's BRDF can be obtained.

\section{Prefilght CAlibration}

\section{A. Radiometric Model}

The aim of the radiometric model of the instrument is to give a synthetic but totally representative description of the physics of the instrument. It characterizes completely the response to the incoming polarized light for each pixel of the CCD matrix, in each spectral band. This model has been described in Hagolle et al. [15], as well as the inversion of the Stokes parameters. Since polarization is not the purpose of this paper, we present here the simplified POLDER radiometric model, which can be used to retrieve the first Stokes parameter, once all the polarization effects have been removed. Let $I$, the normalized total radiance, be defined as

$$
I=\pi \cdot \text { radiance/solar irradiance. }
$$

The Stokes parameters are expressed in normalized radiance units, because accurate calibration of normalized radiances is easier than direct calibration of radiances. A unique solar spectral irradiance profile has been adopted by POLDER project (the solar spectrum recommended by the World Meteorological Organization [41]), and POLDER in-flight absolute calibration is, in fact, a relative calibration to this solar irradiance profile.
The radiometric model can be written

$$
D N_{l p}^{k}=A^{k} \cdot R_{l p}^{k} I_{l p}^{k}
$$

where

$l, p \quad$ line and column numbers of the CCD array;

$k \quad$ spectral band number;

$D N_{l p}^{k} \quad$ digital number measured by the elementary detector $(l, p)$ with a quantization over 12 bits;

$I_{l p}^{k} \quad$ normalized radiance observed by $(l, p)$;

$A^{k} \quad$ absolute calibration coefficient, which accounts for the conversion of normalized radiance units into digital numbers;

$R_{l p}^{k} \quad$ multiangular calibration coefficient: it corresponds to sensitivity variations within the instrument field of view, coming either from the elementary detectors or from the optics.

\section{7)}

This parameter is not easy to measure in-flight and has been split into three terms, and a different in-flight calibration method is used for each term. This is explained in Section IVB.

\section{B. Preflight Calibration}

POLDER preflight calibration [3] gives rise to two main difficulties: 1) the calibration of a bidimensional very wide field of view and 2) the characterization of the polarization sensitivity in the whole field of view. The accuracy of preflight calibrations relies on the following important hardware.

- Two Integrating Spheres: A large integrating sphere for the calibration measurements and a transfer integrating sphere in order to check the air/vacuum stability of the absolute calibration, to control the stability of the reference radiometer and to determine the large integrating sphere nonuniformity.

- A polarizing system which enables the generation of different polarization rates and directions. It is made up of two parallel glass plates which can be oriented around two axes.

- A reference radiometer fitted with filters identical to POLDER ones. The radiometer is used for absolute calibration and has been calibrated with each of the filters in L.C.I.E. (Laboratoire Central des Industries Electriques). This calibration has been operated against a spectrally calibrated source: a standard incandescent lamp and a $\mathrm{BaSO}_{4}$ plate with a good uniformity, and a standard radiometer. The estimated accuracy of this calibration is $\pm 3.5 \%$.

- A monochromator to measure the spectral response of the instrument; the rotation of the grating is synchronous with the instrument imaging cycle, and the emission stability of the lamp is checked all along the measurement. The stability of the response over several measurements is better than $1 \%$ and the variation of the center of the spectral profile is less than $0.3 \mathrm{~nm}$.

The evaluated accuracy of the preflight absolute calibration is $5 \%$. The relative calibration performances are divided in two parts: the high spatial frequency is determined with an 


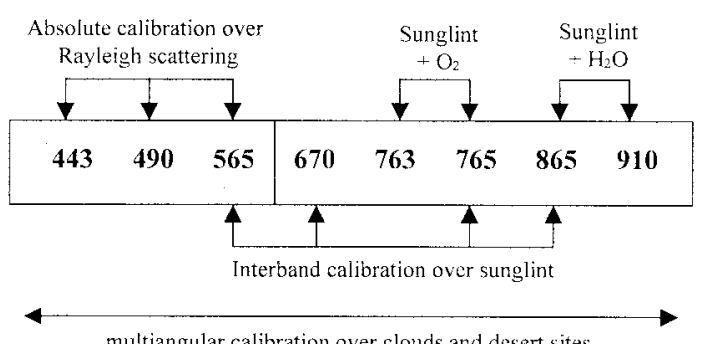

multiangular calibration over clouds and desert sites

Fig. 2. Schematic view of the nominal calibration methods.

uncertainty of $0.1 \%$, while the low spatial frequencies are obtained with an uncertainty of $1 \%$ (because of residual errors in integrating sphere nonuniformity correction). Absolute calibration and thus spectral responses of the filters did not vary when measurements were made in a vacuum chamber. Preflight calibration was also successfully compared to OCTS calibration through a round robin of both projects' calibrating radiometers [29]. However, it was foreseen that because of the ultraviolet irradiation of the external lenses, a slight decrease in the sensitivity of POLDER blue spectral bands could occur (10\% maximum for $443 \mathrm{~nm}$ band after three years, but less than $1 \%$ for 670 ). From all these arguments, it appears that POLDER calibration should only vary slightly after launch but needs to be monitored in-flight to comply with its strict calibration requirements.

\section{INFLIGHT RADIOMETRICAL \\ CALIBRATION: Nominal MethodS}

In order to ensure good in-flight radiometric performances, each calibration parameter of the radiometric model can be measured and monitored using various in-flight calibration methods. Absolute calibration methods (Section IV-A) aim to measure the $A^{k}$ parameter, while multiangular calibration methods (Section IV-B) measure the $p^{k}(\theta)$ and $g^{k} l p$ parameters. Polarization calibration methods are presented in Goloub et al. [13] and Toubbé et al. [43].

Among the various calibration methods that were considered in the preliminary studies for POLDER in-flight calibration, one method for each parameter was chosen as the nominal method (the one having the best error budget). The other methods are used as validation methods to control the results of the nominal methods. This chapter details the procedure, the error budget computed before launch, and the in-flight results for each nominal method. A schematic view of the nominal calibration methods is given in Fig. 2.

\section{A. Absolute Calibration}

POLDER absolute calibration is achieved through an absolute calibration of the "blue" spectral bands (443P, 443, 490, $565)$ using the well-characterized Rayleigh scattering signal over ocean. This absolute calibration is then transferred to the other wavelengths through interband calibration using the specular reflection of the sun over the ocean.

\section{1) Absolute Calibration over Rayleigh Scattering:}

a) Method: The scattering of light by the air molecules (Rayleigh scattering) over ocean is a bright and well-

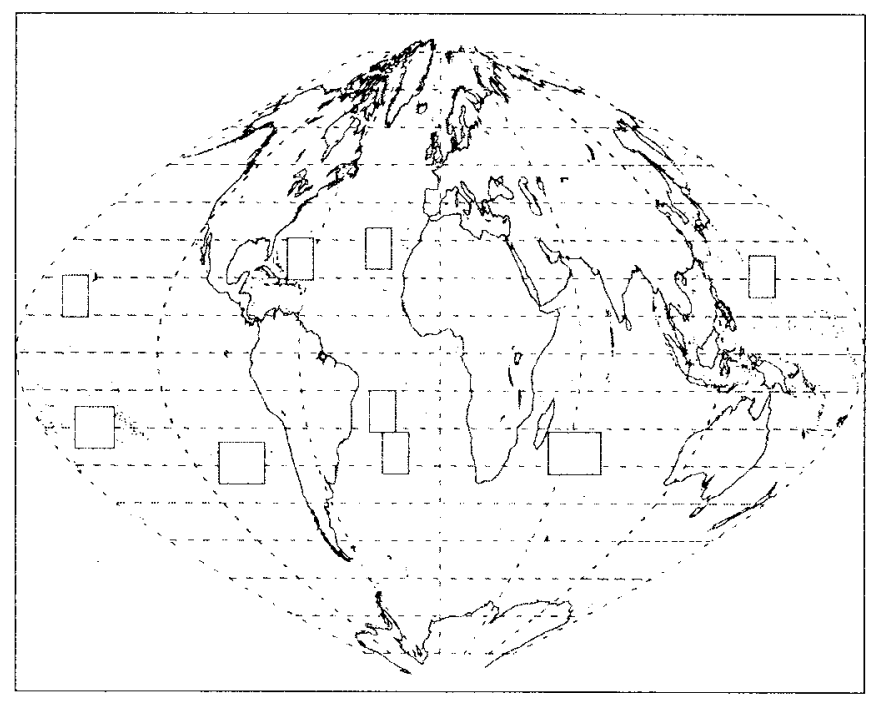

Fig. 3. The boxes on the map are the zones with low chlorophyll concentration where the calibration points for the Rayleigh method are chosen.

characterized target in the lower POLDER spectral bands (443P to 565 spectral bands). For given viewing and solar angles, the Rayleigh scattering can be accurately predicted by radiative transfer codes, and the radiance observed over ocean depends mainly on water-leaving radiance, foam presence, and aerosol amount. The uncertainty that comes from these parameters can be reduced through a strict selection of the pixels used for calibration. The calibration points are selected among POLDER data according to criteria defined to minimize the nonmolecular contribution to the measured signal. They are chosen inside oligotrophic geographic areas having an a priori well-known weak and stable chlorophyll content (oligotrophic waters), with no clouds, a low wind speed, and a low aerosol optical thickness. (Fig. 3 shows the geographical zones.)

Cloudy pixels are eliminated using a cloud screening based on the 865-nm radiance, and meteorological data (ECMWF) are used to select zones with a low wind speed $\left(<5 \mathrm{~ms}^{-1}\right)$. The aerosol content is estimated using the channel $865 \mathrm{~nm}$ : only the observations with a normalized radiance under 0.002 (after subtraction of Rayleigh scattering contribution) are selected for calibration.

Our calibration method is derived from Vermote et al. [39]. The preflight/in-flight variation of the calibration coefficient is obtained through the formula

$\Delta A^{k}=\frac{A_{\text {in-flight }}^{k}}{A_{\text {preflight }}^{k}}=\frac{M I^{k, o z}}{I^{k}\left(v_{w}\right)+T^{k, 865} \cdot\left(M I^{865}-I^{865}\left(v_{w}\right)\right)}$

where

- $M I^{k, o z}$ is the normalized radiance measured by POLDER (level 1 product with preflight calibration) in a band $k$ among $\{443490565\}$. This radiance has been corrected for ozone absorption as described in the Appendix;

- $I^{k}\left(v_{w}\right)$ is the radiance that would be observed above a pure molecular atmosphere. It is a function of geometrical conditions, chlorophyll concentration, and wind speed $v_{w}$. The LUT's are obtained with the SOS code [10]. 
TABLE II

Marine Reflectances Used for Rayleigh CALIBRation

\begin{tabular}{c|c|c}
\hline Spectral Band & $\begin{array}{c}\text { Chlorophyll concentration : } \\
0.17 \mathrm{mg} / \mathrm{m}^{3}\end{array}$ & $\begin{array}{c}\text { Chlorophyll concentration : } \\
0.035 \mathrm{mg} / \mathrm{m}^{3}\end{array}$ \\
\hline 443 & 0.0212 & 0.0344 \\
\hline 490 & 0.0174 & 0.0193 \\
\hline 565 & 0.0052 & 0.0037 \\
\hline
\end{tabular}

Two "extreme" chlorophyll contents $\left(0.035 \mathrm{mg} \cdot \mathrm{m}^{-3}\right.$ and $0.17 \mathrm{mg} \cdot \mathrm{m}^{-3}$ ) are systematically considered for these areas, and the associated water reflectance (Table II) is estimated using the Morel model [23] updated by using new pure water absorption coefficients [27];

- $T^{k, 865}$ is a unitless LUT, function of the viewing geometry, which expresses the ratio between the aerosol contribution in spectral band $k$ and aerosol contribution at $865 \mathrm{~nm}$. This LUT is computed with SOS for two aerosol models [32]: a coastal model with $70 \%$ humidity (C70) and a marine model with $98 \%$ humidity (M98). These models consist of a mixture of sea-salt component and continental component with a log-normal distribution. M98 is an open-sea aerosol model with more sea-salt components than $\mathrm{C} 70$, and with a flatter spectral dependence.

b) Error budget: The main error sources for the theoretical error budget are listed below.

- TOMS measures the ozone amount with an accuracy of 10 Dobson units. The resulting uncertainty on the calibration coefficient is of $0.5 \%$ on $565-\mathrm{nm}$ channel, and far less for 490- and 443-nm channels.

- The wind speed modifies the sunglint geometry and the contribution of the photons scattered by the atmosphere after their reflection over the sea-surface. The uncertainty on wind speed (ECMWF meteorological data) is $2 \mathrm{~m} / \mathrm{s}$ and induces a 0.5 to $1.5 \%$ calibration error on the three channels.

- The surface pressure (meteorological data) is accurately known. (Its bias is estimated under $1 \mathrm{hPa}$.) This leads to a $0.1 \%$ uncertainty on the three channels.

- Aerosol amounts and properties cannot be obtained from external data, but 865 channel is used to discard turbid atmospheres or to estimate aerosol contribution on clear ones. For this error budget, simulations were performed with an aerosol model different from the one used as reference for computing the LUT. These simulations show that the impact of the aerosol model on calibration coefficients is always under 1\%. Calibration errors in the $865-\mathrm{nm}$ band also result in some errors in the aerosol correction: a $5 \%$ error for $865-\mathrm{nm}$ calibration induces a $1 \%$ error on 565 and less for 443 and 490.

- The water-leaving radiance is the main uncertainty for the channel 443. According to bio-optical models and if assumptions on phytoplankton concentrations are globally verified, an error of 50\% on the chlorophyll concentration leads to an uncertainty on calibration coefficient up to $2 \%$ for $443 \mathrm{~nm}$ channel.
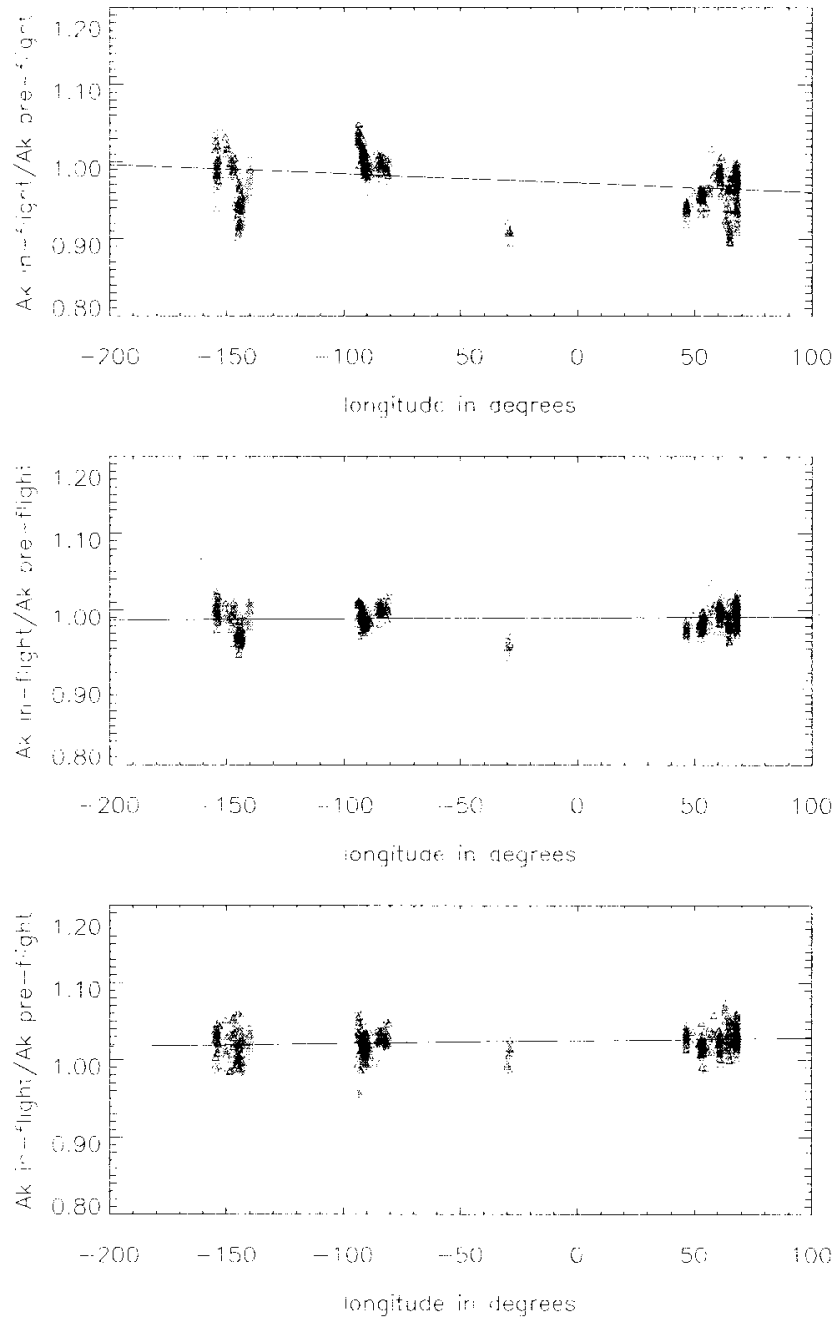

Fig. 4. Absolute calibration elementary results for Rayleigh scattering method as a function of the longitude (with C70 aerosol model and a chlorophyll concentration of $\left.0.035 \mathrm{mg} \cdot \mathrm{m}^{-3}\right)$. Each grey level corresponds to a different location or date of acquisition of the calibration points. All dates are within the first week of November. For $443 \mathrm{~nm}$, the dispersion of the results inside a given site is lower than the dispersion from one site to another. This fact is related to the high variability of water-leaving radiances as a function of chlorophyll concentration. From top to bottom, Rayleigh scattering is $443 \mathrm{~nm}, 490 \mathrm{~nm}, 565 \mathrm{~nm}$.

All these uncertainties lead to a $4 \%$ maximal error for 443 and $3 \%$ for 490 and 565 channels.

c) Results: For each selected calibration point, an elementary calibration result $\Delta A^{k}$ is computed for channels 443, 490, and 565: using all the POLDER level 1 products obtained during one week (100 orbits), more than 200000 elementary results are collected. It is interesting to analyze how the individual measurements vary with the various parameters of the algorithm. Fig. 4 shows that channel 443 is far more sensitive to the variations of chlorophyll concentration with the calibration sites (4\% standard deviation for 443) than channels 490 and 565 , because water reflectance variation as a function of the chlorophyll content is high at $443 \mathrm{~nm}$ and lower around $500 \mathrm{~nm}$. Fig. 5 shows that the estimated calibration coefficients do not depend on the aerosol amount determined with POLDER $865 \mathrm{~nm}$ measurements, when the proper aerosol model is used. According to the aerosol model 


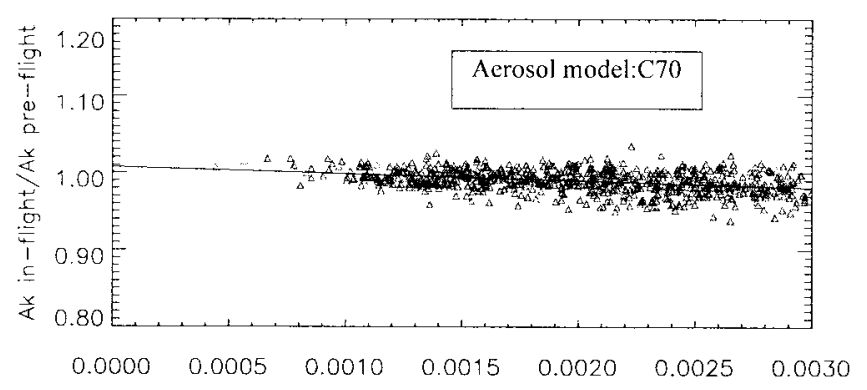

Rayleigh corrected $865 \mathrm{~nm}$ normalized radionce

(a)

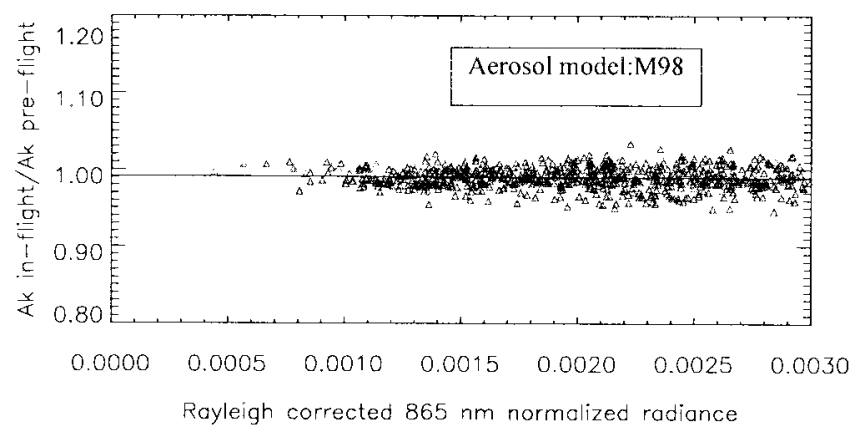

(b)

Fig. 5. Absolute calibration elementary results for Rayleigh scattering method, as a function of the Rayleigh corrected $865 \mathrm{~nm}$ radiance, for two different aerosol models (a) C70 and (b) M98 (modeled radiances simulated with a chlorophyll concentration of $\left.0.035 \mathrm{mg} \cdot \mathrm{m}^{-3}\right)$. The $865-\mathrm{nm}$ radiance is used to determine the effect of the aerosols in the calibrated band. Calibration coefficient and 865-nm radiance are correlated in (a) but not in (b): M98 is likely the most frequent aerosol model in this data set. The Rayleigh method for both plots is $490 \mathrm{~nm}$.

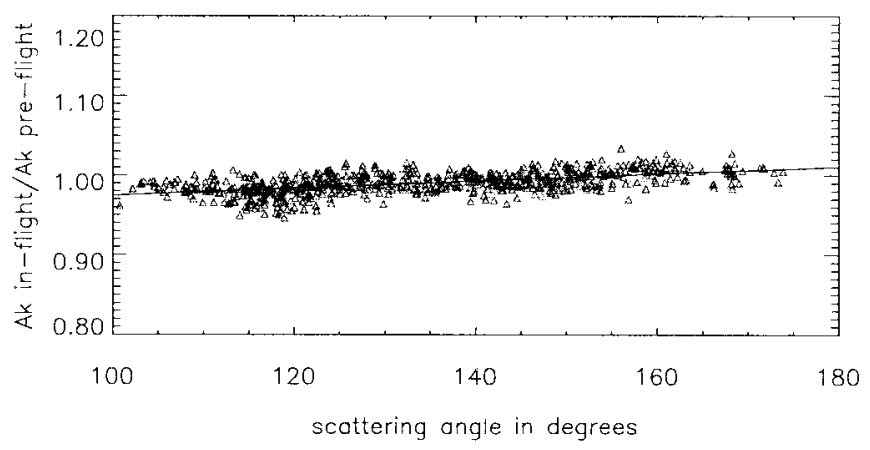

Fig. 6. Absolute calibration elementary results for Rayleigh scattering method as a function of the scattering angle (with $\mathrm{C} 70$ aerosol model and a chlorophyll concentration of $\left.0.035 \mathrm{mg} \cdot \mathrm{m}^{-3}\right)$. Here, a correlation exists between the calibration elementary results and the scattering angle. This correlation appears also for the 443-nm spectral band and could be related to directional effects in water-leaving radiances (considered as Lambertian in the algorithm). The Rayleigh scattering is $490 \mathrm{~nm}$.

used in the simulations, the $A^{k}$ values differ by $1.5 \%$ for 565 and by less than $1 \%$ for 490 and 443 . Finally, calibration coefficients almost linearly depend on the scattering angle (Fig. 6): some effects might not be perfectly modeled, such as directional variations of water-leaving radiance (assumed to be Lambertian). Many more parameters have been studied, such as wind speed, ozone amount, or geometric conditions, but the estimated absolute calibration is not correlated to any of them.
To determine the in-flight calibration coefficients, the elementary results collected during one week are averaged. Four simulations are performed using each "extreme" chlorophyll content and both aerosol models, and this is done for three sets of one week of data, leading to 12 calibration results. The $A^{k}$ (in-flight) $/ A^{k}$ (preflight) ratio is the mean value of these 12 results (Table III). The zero-peak dispersion of the averaged results is $4 \%$ for $443,2 \%$ for 490 , and $3 \%$ for 565 . The higher dispersion for 443 is related to the impact of water-leaving radiance: the thresholds imposed both on the contribution of aerosols at $865 \mathrm{~nm}$ and on the wind speed (smaller than $5 \mathrm{~m} / \mathrm{s}$ ) prevent the effect of these parameters on calibration coefficients from being greater than $2 \%$. The uncertainty on oceanic water reflectance seems to be greater than expected in this band.

However, the Rayleigh scattering method is an efficient method for the absolute calibration of optical instruments without using in-situ measurements. This method provides calibration coefficients with a 3-4\% uncertainty for spectral bands 490 and 565 , but a better knowledge of the cartography of water-leaving radiance at $443 \mathrm{~nm}$ is required to obtain the same results for 443 . Of course, the use of oligotrophic waters is not the ideal case for the calibration of 443 channel since the water-leaving radiance is high. But it is not easy to find ocean zones away from the coasts with high and stable chlorophyll concentrations. Another way of enhancing the results is to use in-situ measurements: Fougnie et al. [11] have acquired in-situ data of water-leaving radiances, using SIMBAD instruments quasi-simultaneously with POLDER acquisitions.

2) Interband Calibration over Sunglint: This method uses the specular reflection of the sun (sunglint) on the sea-surface to transfer the calibration of 565 to the spectral bands 670,763 , 765,865 , and 910 (Fig. 2). The sunglint is spectrally flat and has a high radiance that limits the influence of other parameters such as water leaving radiance or aerosols. The sunglint radiance depends mainly on the sea-surface roughness, which is related to the wind speed. For a mirror-like sea-surface, the sunglint radiance would be very high in the exact sunglint direction and very low outside of it, whereas an agitated sea-surface scatters a lower radiance in a wider cone. The $565-\mathrm{nm}$ radiance is used to estimate the sea-surface roughness (via a radiative transfer code). The surface roughness is then used to estimate the radiance for 670,765 , and 865 spectral bands. The calibration of 763- and 910-nm channels requires ancillary information to evaluate the high atmospheric absorption: surface pressure (for 763) and atmospheric water vapor content (for 910) derived from ECMWF analysis. The sunglint method can also be used to calibrate 443 and 490 spectral bands with of a reduced accuracy, just to verify that the results are consistent with the Rayleigh scattering results.

a) Calibration of 670-, 765-, and 865- $\mathrm{nm}$ spectral bands:

i) Method: The radiance measured in 565, 670, 765, and 865 spectral bands is first corrected for molecular absorption as described in the Appendix. Then, the sunglint radiance observed by POLDER in each spectral band $k$ within 670, 765 , and 865 is estimated at the top of atmosphere (TOA) and is compared to the real POLDER measurement. 
TABLE III

Absolute Calibration Results $\Delta A^{k}$ Obtained with the Nominal In-Flight Calibration Methods. Sunglint Calibration is an Interband Calibration Method and Thus Needs a Reference (565) to Become an Absolute Calibration Method. The $\Delta A^{k}$ Obtained with Rayleigh Scattering for 565 is Copied in Italic in the Sunglint Column. Results Reported in "In-Flight" Column are Operationally Used in POLDER Level 1 Products

\begin{tabular}{c||c|c|c||c}
\hline Spectral band & Pre-Flight & Rayleigh Scattering & Sunglint & $\begin{array}{c}\text { In-Flight } \\
\text { V2.0 }\end{array}$ \\
\hline \hline 443 & 1.00 & 0.95 & & 0.97 \\
\hline 490 & 1.00 & 0.99 & & 0.99 \\
\hline 565 & 1.00 & 1.035 & 1.035 & 1.035 \\
\hline 670 & 1.00 & & 1.03 & 1.03 \\
\hline 763 & 1.00 & & 1.025 & 1.025 \\
\hline 765 & 1.00 & & 1.035 & 1.035 \\
\hline 865 & 1.00 & & 1.05 & 1.05 \\
\hline 910 & 1.00 & & 1.025 & 1.05 \\
\hline \hline
\end{tabular}

Equation (3) shows the different parameters that control the TOA normalized radiance $I_{\mathrm{spe}}^{k}$ in the specular direction

$$
I_{\mathrm{spe}}^{k}=I_{m}^{k}+I_{a}^{k}+\left(I_{g}+I_{w}^{k}+I_{f}\right) T_{m}^{k} \cdot T_{a}^{k}
$$

$I_{g}$ is the normalized radiance of the sunglint with no atmosphere, $I_{m}^{k}$ is the radiance of the light scattered by the molecules, $I_{a}^{k}$ corresponds to aerosols scattering, $T_{m}^{k}$ and $T_{a}^{k}$ are the scattering transmission of the molecules and aerosols, and the water-leaving radiance $I_{w}^{k}$ and the foam radiance $I_{f}$ are modeled by Lambertian contributions [19]. (Actually, the scattering transmission factors are not exactly the same when applied to sunglint highly directional target, or to a quite Lambertian target like foam, but the equation has been simplified for better clarity).

$I_{g}$ depends on the viewing geometry and on the surface roughness (related to wind speed), but not on the spectral band [8]. However, because $I_{m}^{k}$ is not negligible in comparison to $I_{g}$, the TOA reflectances depend on the spectral bands and this dependence varies with the sea-surface roughness. An estimate of surface roughness is thus necessary to perform the interband calibration.

Equation (3) is just an approximation limited to single scattering. To accurately compute the sunglint radiance $I_{\text {spe }}^{k}$ observed by POLDER, (4) is used, for which all the terms are obtained using LUT's obtained through radiative transfer simulations.

A first LUT is used to estimate the wind speed from the 565$\mathrm{nm}$ radiance. The LUT is computed assuming the atmosphere is purely molecular, and using the SOS method [10], which takes into account multiple scattering in the atmosphere and multiple reflections on the sea-surface. The sea-surface is represented by a Lambertian contribution (the water-leaving radiance), and by the Cox and Munk model which relates the wind speed to the sea-surface roughness. The simulations are made for a dense grid of geometrical conditions, and for 15 different wind speeds (from 1 to $15 \mathrm{~m} / \mathrm{s}$ ). The first step of the methods seeks the wind speed $v_{w}$ that corresponds to a radiance equal to the one measured at $565 \mathrm{~nm}$. The obtained wind speed may be not very accurate and is just an indicator of the sea-surface roughness.
Then the radiance for the bands 670,765 , and 865 is estimated using (4)

$$
I_{\mathrm{spe}}^{k}=I_{\mathrm{PMA}}^{k}\left(v_{w}\right)+\Delta I^{k}\left(I_{\mathrm{PMA}}^{k}\left(v_{w}\right), M I_{\mathrm{atm}}^{670}, M I_{\mathrm{atm}}^{865}\right) .
$$

The first term of (4) is the sunglint radiance $I_{\mathrm{PMA}}^{k}\left(v_{w}\right)$ that would be observed with a pure molecular atmosphere (PMA) with no aerosol and a surface wind-speed $v_{w}$. A second LUT is used to derive the PMA radiance in spectral band $k$ from the wind speed.

The second term of (4) is an empirical correction of the first term. $\Delta I^{k}$ accounts for the effect of atmospheric aerosols on the sunglint radiance, through the use of an empirical model obtained by mean squares minimization. This model depends on the POLDER measurements $M I_{\mathrm{atm}}^{670}$ and $M I_{\mathrm{atm}}^{865}$ in a viewing direction outside the sunglint, and on the sunglint radiance $I_{\text {PMA }}^{k}\left(v_{w}\right) . M I_{\mathrm{atm}}^{865}$ gives information on the optical depth of aerosols, and combined with $M I_{\mathbf{a t m}}^{670}$, on the Angstrom coefficient $\alpha$ which accounts for the spectral variation of aerosol optical depth.

The coefficients of the model of the aerosol effect are derived statistically through a mean square minimization of the difference between the two parts of (4). A regression is performed for each node of a very dense grid of viewing geometry (sunglint and off-sunglint viewing and solar angles), and each regression is obtained from simulations with the SOS method, performed for a large set of aerosol models [six Shettle and Fenn models [32]: C70, C90, C98 (coastal models) and M70, M90, M98 (maritime models)] [14], [32], optical thickness (four values: $0.025,0.05,0.075,0.1$ ) and wind speeds $(2,5,10,15)$. These simulations apply not only to the exact specular direction, but also to a small cone around this direction.

ii) Error Budget: Various error sources limit the accuracy of the interband calibration method. The error budget presented below is computed with simulated data for $k=865$ $\mathrm{nm}$ (budget for 670 would be even better); the reported errors are averaged over 96 cases (six aerosol models, four aerosol optical thickness, and four wind speeds) for solar zenith angles between 20 and $40^{\circ}$. This error budget has been computed for the exact specular direction, but other simulations have shown that the accuracy remains stable for an angular distance to 
the specular point lower than $3^{\circ}$. The residual rms error after regression over 96 simulation cases is about $0.1 \%$.

\section{Instrumental Errors:}

Noise: The effect of instrumental noise is completely negligible, since more than 1000 calibration points are averaged to compute each absolute calibration coefficient.

Calibration errors: An error in the absolute calibration of the 565 channel introduces an error on the estimated surface roughness and therefore on the PMA estimation of the sunglint radiance. If we have an absolute calibration bias of $3 \%$ for 565 , simulations show that the bias for 865 is also $3 \%$, leading to no error on the interband calibration (this is not true if 443 is used as a reference). Errors on the initial calibration of 670 and 865 impact on the estimation of the aerosol influence. Given an error $\left(\Delta A^{670}, \Delta A^{865}\right)_{1}$, applying the interband calibration method gives a smaller new error $\left(\Delta A^{670}, \Delta A^{865}\right)_{2}$ and the process needs to be iterated. Final errors are below $0.5 \%$.

\section{Geophysical Errors:}

Foam Contribution: To evaluate the influence of foam radiance, the coefficients are applied on two different data sets, one with foam scattering and one without. The error budget was made assuming that foam scattering is spectrally flat, and the impact on the budget is negligible. Some new studies have shown that the foam might not be spectrally flat, so we discarded calibration points having a wind speed higher than $5 \mathrm{~m} / \mathrm{s}$.

Chlorophyll Concentration: To estimate the impact of a realistic error on the chlorophyll concentration, the coefficients calculated with the radiance of sea water with a chlorophyll concentration of $0.05 \mathrm{mg} / \mathrm{m}^{3}$ (water-leaving normalized radiance of 0.0042 for 565), were applied to a simulation with a water leaving radiance associated to a chlorophyll concentration of $0.10 \mathrm{mg} / \mathrm{m}^{3}$. The resulting error is $0.3 \%$.

Atmospheric Pressure: The coefficients are calculated for the standard atmospheric pressure at sea level. They were applied on simulations calculated with a higher pressure (10 $\mathrm{hPa}$, more than the expected rms error on the ECMWF meteorological data). Impact of this error is about $0.1 \%$.

Gaseous Absorption: An uncertainty of $20 \%$ on water vapor amount has no impact on the method, but an uncertainty of $5 \%$ on ozone amount induces an error on the gaseous transmission, which leads to an error on $I_{\mathrm{spe}}^{565}$ of less than $0.1 \%$.

Aerosol Model: The coefficients $a_{m}^{k}$ obtained by fitting various aerosol models were applied to simulations performed with a unique coastal aerosol model. The resulting error is about $0.1 \%$.

The total error budget gives an interband calibration accuracy better than $1 \%$, and an absolute calibration error of $3.5 \%$ for 865 assuming $565 \mathrm{~nm}$ absolute calibration is accurate to $3 \%$.

b) Calibration of 763- and 910-nm spectral bands: 763 and 910 channels are centered on gaseous absorption bands: oxygen A-Band and 910-nm water vapor absorption band, respectively. The absolute calibration of the 763-nm (re- spectively, 910-nm) band can be derived from the absolute calibration of the 765-nm (respectively, 865-nm) band over the sunglint, provided the atmospheric gaseous absorption is known.

i) Calibration of 763-nm band: Owing to the fact that $\mathrm{O}_{2}$ proportion is constant within the atmosphere, the $\mathrm{O}_{2}$ absorption can be related to the atmospheric pressure at sea level in clear sky conditions. Based on line-by-line simulations (using the spectroscopic data from HITRAN96 database [28]) a polynomial model is derived that links the $\mathrm{O}_{2}$ transmission at $765 \mathrm{~nm}$ to the sea-surface pressure and to the air-mass factor. The atmospheric pressure is obtained with ECMWF analysis, and the $\mathrm{O}_{2}$ transmission derived through this method, $T_{O 2}^{\mathrm{ECMWF}}$, is compared to that derived from the POLDER measurements, $T_{\mathrm{O} 2}^{763}$. From the two equations in the Appendix, $T_{O 2}^{763}$ can be written as

$$
T_{O_{2}}^{763}=\frac{(1-A) \frac{M I^{763}}{M I^{765}}}{1-A \frac{M I^{763}}{M I^{765}}} \frac{T_{O_{3}}^{765} \cdot T_{H_{2} O}^{765}}{T_{O_{3}}^{763} \cdot T_{H_{2} O}^{763}}
$$

where $M I^{763}$ and $M I^{765}$ are the POLDER radiances and where the other parameters are described in the Appendix. Finally, the variation of the absolute calibration coefficient at $763 \mathrm{~nm}$ is expressed as

$$
\Delta A^{763}=\frac{A_{\text {in-flight }}^{763}}{A_{\text {preflight }}^{763}}=\frac{T_{O_{2}}^{763}}{T_{O_{2}}^{\mathrm{ECMWF}}} .
$$

Since the 765-nm band is involved in the computation of $T_{O 2}^{763}$, it may be necessary to iterate the method in case of a large variation of the calibration coefficient of this band.

The error sources of this interband calibration are quite small: they mainly come from the aerosol scattering, (but we still select only low aerosol contents using an off-sunglint measurement at $865 \mathrm{~nm}$ ), from the accuracy of the surface pressure (less than $1 \mathrm{hPa}$ of bias), and from the quality of absorption corrections. However, the main error for $763 \mathrm{ab}-$ solute calibration results from the 765-nm absolute calibration error. But, as $763 \mathrm{~nm}$ is never used alone but always with 765-nm band to determine apparent pressure [37], POLDER data users are only interested by 763/765 interband calibration that should be better than $1 \%$.

ii) Calibration of 910- $\mathrm{nm}$ band: This band is calibrated in a similar way as 763-nm band, replacing surface pressure by vertical profiles of atmospheric water vapor content, since it has been shown that total water vapor absorption does not depend only on the total water vapor amount but also on its vertical distribution. Derivation of water vapor absorption from the vertical profile is described in Bouffies et al. [2].

These vertical profiles are obtained from ECMWF analysis every $6 \mathrm{~h}$ and interpolated to the date of acquisition. Although the data are known to be inaccurate over the oceans where radiosoundings are very sparse, some studies [25] have shown they are globally unbiased. The corresponding error should therefore be reduced to $1.5 \%$ by accumulating a large number of calibration points. The 910 and 865 spectral bands are not as close as 763 and 765 , but effects of spectral variations of 
the target between both wavelengths are very low thanks to the use of sunglint.

Because of their high altitude (above water vapor), stratospheric aerosols could induce some errors in the estimation of the total water vapor absorption, but POLDER was calibrated in a period of very low stratospheric aerosol content. The amount of tropospheric aerosols is limited by using only the pixels which have a $865-\mathrm{nm}$ radiance in an off-sunglint viewing direction under 0.005 (after correction of the molecular scattering contribution). As shown in [40], 6S simulations show that the total impact of aerosols on the error budget is less than $0.3 \%$.

The choice of this sunglint method is arguable because of radiosoundings scarcity in the open ocean, but it combines two advantages: spectral variation of surface reflectance is far better known than that of any land surface, and the effects of aerosols are lower because selecting clear atmospheres is easier. Total error budget for this calibration method is estimated to $1.6 \%$. Vesperini et al. [40] have carried out a validation of the calibration of band 910 by comparing water vapor content derived from POLDER to water vapor measured by radiosoundings.

c) Results: The sunglint interband calibration uses the same kind of target as the molecular scattering method: very clear ocean scenes with a very low aerosol optical thickness. Of course, a third selection criterion has been added: the viewing direction of the calibration point must be within a cone of $3^{\circ}$ of radius, centered on the specular direction $\left[\theta_{s}=\right.$ $\theta_{v}, j=180^{\circ}$ (Fig. 14)]. For higher values, the dispersion of the results increases quickly, indicating that the geometrical modeling of the sunglint is less accurate. The off-sunglint 865$\mathrm{nm}$ maximal radiance threshold $(0.005$ in normalized radiance units) is a little higher than for calibration over molecular scattering.

The dispersion of the elementary results (Fig. 7) is very low, except for $910 \mathrm{~nm}$ because of the dispersion of meteorological data. A complete analysis of the elementary measurements does not show any significant dependency of the elementary results on any of the algorithm parameters. For example, the correlation between the measured calibration coefficient and the aerosol normalized radiance (Fig. 8) is very low, indicating that the aerosol scattering has been properly corrected. Some correlation was found, however, between A865 and the atmospheric water vapor amount. The correlation disappeared when we decided not to correct for the absorption by water vapor continuum (the existence of this continuum of absorption in the near infrared is questionable). To prevent any impact of this parameter on calibration accuracy, only low water vapor contents have been selected.

To determine the in-flight calibration coefficients, the elementary results collected during one week are averaged. Averaged results have been obtained for the five channels over five periods of one week distributed during the whole life of the instrument. The results given in Table III are obtained after having calibrated the 565 reference band over Rayleigh scattering. Fig. 8 shows that the dispersion of the averaged results is small and Fig. 9 shows that interband calibration does not evolve with time.
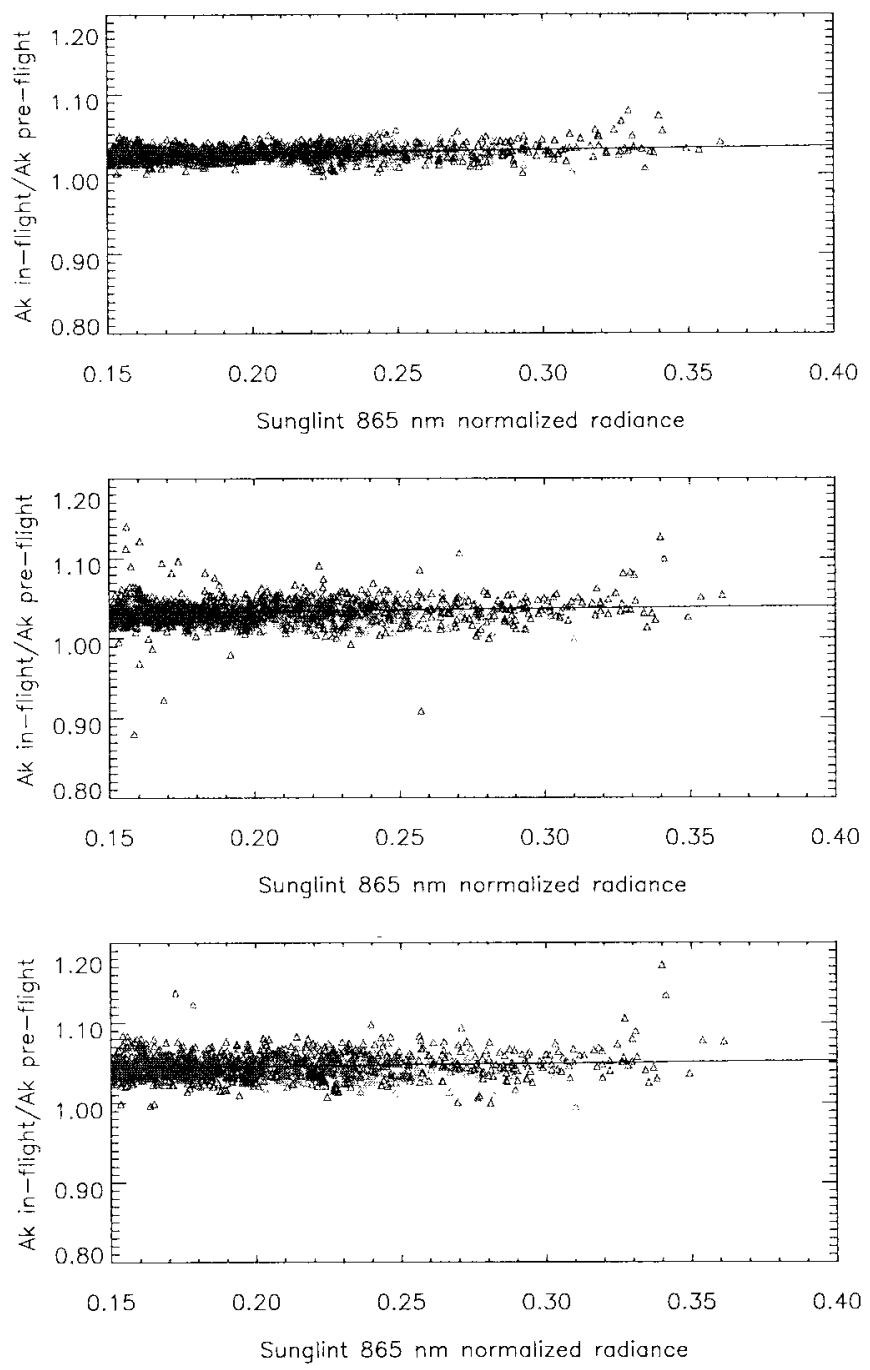

Fig. 7. Absolute calibration elementary results for sunglint interband method as a function of sunglint $865-\mathrm{nm}$ radiance (for all the calibration points selected during the first week of November 1996). Standard deviation is very low for 670-nm calibration $(0.8 \%)$ and increases slightly when spectral distance to 565 reference band increases $(1.5 \%$ for $865 \mathrm{~nm})$. The curves show no correlation between calibration results and sunglint radiance at $865 \mathrm{~nm}$. From top to bottom, the Sunglint method is $670 \mathrm{~nm}, 765 \mathrm{~nm}$, and $865 \mathrm{~nm}$.

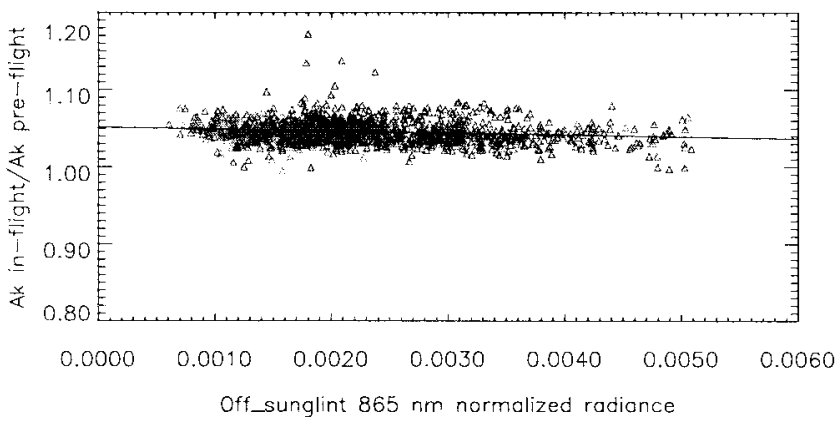

Fig. 8. Absolute calibration elementary results for sunglint interband method as a function of the Rayleigh corrected 865 -nm radiance in an off-sunglint direction (for all the calibration points selected during the first week of November 1996). Correlation with the aerosol content is very small: this validates the aerosol effect correction. The Sunglint method is $865 \mathrm{~nm}$.

The results obtained for the 910-nm spectral band show a rather high dispersion (4\%) which comes from the limited accuracy of the water vapor information from ECMWF data. 


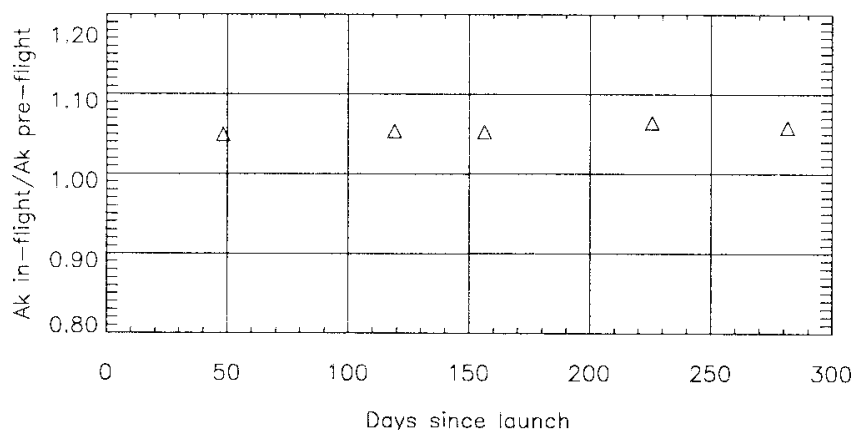

Fig. 9. Absolute calibration averaged results for sunglint interband method as a function of time: each point is the average of all the elementary results obtained with one week of POLDER data (100 orbits). The dispersion of the results is very low and the curve shows no drift during the whole life of POLDER instrument. The Sunglint method (averaged results) is $865 \mathrm{~nm}$

The results obtained in the other spectral bands are excellent and a great confidence can be given to this calibration method.

The same calibration method can be applied using 443P instead of 565 as the reference band. This leads to a degraded calibration performance because of water-leaving radiance uncertainty and because of the higher spectral distance between $443 \mathrm{P}$ and the near infrared spectral bands. However, this method enabled us to check 443P/565 interband calibration with an independent method. Assuming $\Delta A^{k}(565)=1.035$ (as obtained with Rayleigh scattering method), the interband calibration gives 0.96 for $443 \mathrm{P}$, very close to 0.95 obtained with Rayleigh scattering method (Table V).

\section{B. Multiangular Calibration}

Multiangular calibration is defined as the process of estimating the sensitivity variations at different points of POLDER wide field of view. Usually, the multiangular calibration methods consist in having the instrument look at a spatially uniform landscape, which can be an internal source (VGT/SPOT4, SPOT) or natural targets such as snow fields (SPOT). For a wide field-of-view instrument $(2400 \mathrm{~km} * 1800 \mathrm{~km})$, a continuous uniform landscape does not exist. As POLDER is not equipped with an on-board calibration device, new methods have been defined to simulate a spatially uniform landscape.

However, no method was found able to completely calibrate the sensitivity differences for all POLDER detectors. Different methods are used to calibrate the low spatial frequencies and the high spatial frequencies of the multiangular calibration coefficients. This explains why multiangular calibration coefficients $R_{l p}^{k}$ in the radiometric model have been split into three terms:

$$
R_{l p}^{k}=p^{k}(\theta) \cdot g m f_{l p}^{k} \cdot g h f_{l p}^{k}
$$

- $p^{k}(\theta)$ expresses the low-frequency variations of the optic transmission which decreases slightly when the viewing angle $\theta$ increases (Fig. 10). Its measurement is performed over desert sites as described below and the targeted accuracy is $1 \%$. Desert sites are neither uniform enough nor frequent enough to be used for high frequency.

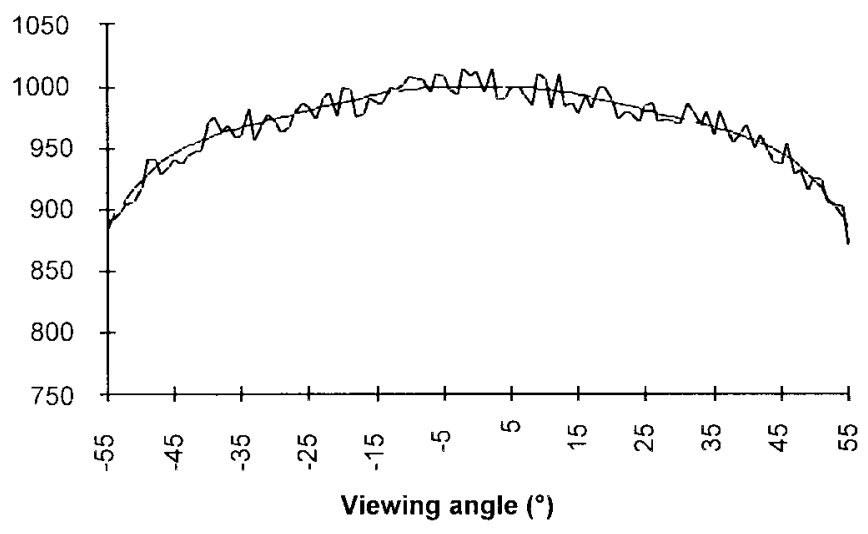

Fig. 10. Typical response on a radial section of the CCD $\left(p^{k} \cdot g m f_{l p}^{k} \cdot g h f_{l p}^{k}\right)$. The smooth line represents the low-frequency variation of multiangular calibration $p^{k}$.

TABLE IV

Center Locations of the Desert Sites (Longitude $>0$ for East Location)

\begin{tabular}{l|c|c}
\hline Site Name & Latitude $\left({ }^{\circ}\right)$ & Longitude $\left(^{\circ}\right)$ \\
\hline Arabial & 18.88 & 46.76 \\
\hline Arabia2 & 20.13 & 50.96 \\
\hline Arabia3 & 28.92 & 43.73 \\
\hline Sudan1 & 21.74 & 28.22 \\
\hline Niger1 & 19.67 & 9.81 \\
\hline Niger2 & 21.37 & 10.59 \\
\hline Niger3 & 21.57 & 7.96 \\
\hline Egypt1 & 27.12 & 26.10 \\
\hline Libya 1 & 24.42 & 13.35 \\
\hline Libya2 & 25.05 & 20.48 \\
\hline Libya3 & 23.15 & 23.10 \\
\hline Libya4 & 28.55 & 23.39 \\
\hline Algeria1 & 23.80 & -0.40 \\
\hline Algeria2 & 26.09 & -1.38 \\
\hline Algeria3 & 30.32 & 7.66 \\
\hline Algeria4 & 30.04 & 5.59 \\
\hline Algeria5 & 31.02 & 2.23 \\
\hline Mali1 & 19.12 & -4.85 \\
\hline Mauritania1 & 19.40 & -9.30 \\
\hline Mauritania2 & 20.85 & -8.78 \\
\hline
\end{tabular}

- $g h f_{l p}^{k}$ refers to high-frequency variations of the sensitivity of the elementary detectors. It is measured over clouds. Its targeted accuracy is $0.1 \%$. Of course clouds are not Lambertian targets, and their BRDF depends on the type of cloud: the low-frequency variation of the multiangular calibration cannot be estimated by this method.

- $g m f_{l p}^{k}$ refers to low-frequency variations in the sensitivity of the elementary detectors that cannot be modeled by a polynomial function of the viewing angle. The targeted accuracy is $1 \%$. Since this parameter is mainly linked to heterogeneity in the CCD matrix, it is expected not to vary after launch, and preflight calibration is used for this parameter. However, calibration over desert sites could be used to detect an unlikely large variation. 
TABLE V

Comparison of the Nominal In-Flight Absolute Calibration Results $\Delta A^{k}$ with the Validation Method Results. Values in Italic Indicate that the Corresponding Band is used as a Reference for an Interband Method. Italic Value is Copied from "In-Flight" Column

\begin{tabular}{c|c|c|c|c|c||c}
\hline \hline Spectral band & $\begin{array}{c}\text { OCTS } \\
\text { (pre-flight) }\end{array}$ & $\begin{array}{c}\text { OCTS } \\
\text { (in-flight) }\end{array}$ & Sunglint & Clouds & ATSR-2 & $\begin{array}{c}\text { In-Flight } \\
\text { (Used in level 1) }\end{array}$ \\
\hline \hline 443 & 0.96 & 0.955 & 0.96 & 1.01 & & 0.97 \\
\hline 490 & 0.92 & 0.975 & 0.98 & 1.02 & & 0.99 \\
\hline 565 & 1.045 & 1.01 & 1.035 & & 1.06 & 1.035 \\
\hline 670 & 1.01 & 1.09 & & 1.03 & 1.035 & 1.03 \\
\hline 765 & 1.01 & 1.12 & & & & 1.035 \\
\hline 865 & 0.98 & 1.28 & & & 1.00 & 1.05 \\
\hline \hline
\end{tabular}

1) Low-Frequency Multiangular Calibration over Desert Sites: Stable desert areas of the Sahara and Saudi Arabia can potentially be used as calibration test sites in the solar reflected spectrum. Such sites have already been used to monitor the calibration temporal drifts of the AVHRR [18], [30], [36], ATSR-2 [34], Meteosat [5], [24], and HRV/SPOT sensors [17]. They can also be used to estimate the multiangular calibration of wide field of view sensors equipped with CCD arrays such as POLDER. This requires a good characterization of the directional variations of their top-of-atmosphere reflectances, to account for the variations of the solar or viewing configurations between measurements.

a) Method: A procedure has been defined to select 100 $\times 100 \mathrm{~km}^{2}$ desert areas in North Africa and Saudi Arabia [6] using a spatial uniformity criterion in Meteosat-4 visible data. Twenty such sites (Table IV) meet this criterion within 3\%. The temporal stability of the spatially averaged reflectance of each selected site has been investigated at seasonal and hourly time scales with multitemporal series of Meteosat4 data. It was found that the temporal variations of an $8-15 \%$ typical peak-to-peak amplitude (in relative value) were mostly controlled by directional effects. Once the directional effects are removed, the residual root mean square variations, representative of random temporal variability, are in the order of $1-2 \%$ in relative values.

Second, a field experiment [7] took place in February-March 1993 to characterize the BRDF of four desert sites (Algeria 2, Algeria 3, Algeria 4, and Algeria 5). The purpose of this experiment was to measure the BRDF of the sites to use them as a reference for multiangular calibration of optical sensors. Bidirectional measurements of the surface reflectance (and also polarization) were collected in three different planes (principal, perpendicular, and $45^{\circ}$ ) at four wavelengths: $450,650,850$, and $1650 \mathrm{~nm}$. Then, the surface reflectance measurements have been adjusted against an empirical model of BRDF defined as

$$
\begin{aligned}
\rho_{T O A}^{k}\left(\theta_{s}, \theta_{v}, \varphi\right)= & a^{k}+\theta_{s} \theta_{v} \frac{\cos \theta_{s} \cos \theta_{v}}{\cos \theta_{s}+\cos \theta_{v}} \\
& \cdot\left(b^{k} \cos \varphi+\theta_{s} \theta_{v}\left(c^{k}+d^{k} \cos ^{4} \varphi\right)\right)
\end{aligned}
$$

where $\left(\theta_{s}, \theta_{v}, \varphi\right)$ are, respectively, the solar zenith angle, the viewing zenith angle, and the difference of solar and viewing azimuth angles, and where the coefficients $a^{k}, b^{k}, c^{k}$, and $d^{k}$ are determined by a least square regression (more details about this model are included in [7]). A spectral linear interpolation is then performed to adapt the model to POLDER spectral bands.

The TOA surface reflectance $\rho^{*}$ in each spectral band is then estimated by decoupling the absorption and scattering effects

$$
\rho_{T O A}^{k}\left(\theta_{s}, \theta_{v}, \varphi\right)=T_{g}\left(\theta_{s}, \theta_{v}\right) \rho_{\text {surf }+ \text { atm }}^{k}\left(\theta_{s}, \theta_{v}, \varphi\right) \text {. }
$$

$\rho_{\text {surf+atm }}^{k}\left(\theta_{s}, \theta_{v}, \varphi\right)$ is computed with the SOS code [10] with as inputs i) the atmospheric optical thickness in the POLDER bands (derived from the barometric pressure for the Rayleigh scattering and, for the aerosols, from the extinction measurements during the field campaign), ii) an aerosol model (a Junge size distribution associated with the Angstrom coefficient derived from the extinction measurements, and a standard refractive index of the aerosols chosen to be that of silica) and iii) the BRDF measured during the field campaign. The gaseous absorption $T_{g}$ is derived from a climatology of absorbing gas concentrations for ozone, and oxygen and water vapor absorption are estimated using POLDER 763 and 910 spectral bands as explained in the Appendix.

To obtain an experimental error budget, the retrieved BRDF has been compared to the reflectance measurements made by AVHRR in channel 1 for the four desert sites (Algeria 2, Algeria 3, Algeria 4, and Algeria 5) [7]. The AVHRR instrument is used as a reference, since its only detector does not introduce calibration variation within the field of view. Using the revolution symmetry of the polynomial function $p(\theta)$, this comparison gives a zero-peak error of $1 \%$ for high sun zenith angles $\left(50-60^{\circ}\right)$ that correspond to the range observed during the field campaign. Unfortunately, this budget does not apply to 443-nm band, which is not covered by AVHRR channel 1.

Once the BRDF of each site is obtained for POLDER spectral bands, it is possible to perform POLDER multiangular calibration. After discarding cloudy acquisitions, selected POLDER data are averaged over the site surface $(15 \times$ 15 POLDER pixels), and an estimation of the evolution of calibration coefficients is performed for each viewing direction using the following formula:

$$
\Delta(A p(\theta))^{k}=\frac{A_{\text {in-flight }}^{k} \cdot p_{\mathrm{in}-\text { flight }}^{k}(\theta)}{A_{\text {preflight }}^{k} \cdot p_{\text {preflight }}^{k}(\theta)}=\frac{M \rho^{k}}{\rho_{T O A}^{k}\left(\theta_{s}, \theta_{v}, \varphi\right)}
$$


where $M \rho^{k}$ is the reflectance measured by POLDER and comes from the level 1 product obtained with preflight calibration, $p_{\text {preflight }}^{k}(\theta)$ is low frequency preflight calibration, and $p_{\text {in-flight }}^{k}(\theta)$ is the in-flight calibration. Of course, during a clear day, up to 12 different satellite viewing angles $\theta$ (Fig. 14) are obtained for a given desert site. $\Delta(A p(\theta))^{k}$ is computed for each reference site as a function of the viewing angle and a polynomial fit is performed to estimate the low-frequency polynomial $p^{k}(\theta)$. Even if absolute calibration coefficients are present in the above equation, it is not possible to derive an accurate absolute calibration from this method, since absolute calibration was not the aim of the in-situ campaign. However, if EOS had worked longer, this method could have been used to verify multitemporal calibration, i.e., variations of absolute calibration with time.

b) Results: The data have been acquired during four weeks in November 1996, and a second set during the two first weeks in January 1997. More than 650 images have been used on the 20 desert sites to perform the multiangular calibration. For each image, the areas corresponding to the reference sites are extracted and then automatic tests are used to discard clouds. Six tests were used but the most efficient are:

- a spectral index computed between bands 865P and 443P (desert TOA reflectance increases with the wavelength whereas clouds are whiter);

- statistics on the spatial uniformity of the measurements inside each desert site.

Since only four of the 20 selected desert sites have been characterized with in-situ measurements, the nominal method was to use the four Algerian sites for calibration and those having a similar behavior among the others. In Fig. 11(a), the results obtained on one of the Algerian sites (Algeria 2) are plotted. These sites have been affected by bad weather during November, 1996, and only a small amount of cloudfree data has been collected, but moreover, the results have a great standard deviation. Multiangular calibration seems to be correct (except for 443), but the forecast accuracy of $1.5 \%$ cannot be achieved with this data set. For 443 spectral band, multiangular calibration seems to be correct up to $45^{\circ}$. For higher viewing angles, the calibration seems to decrease, but it is difficult to prove that the error comes from POLDER multiangular calibration: the data in this zone were only collected with two cloud-free acquisitions (one clear day gives 12 different viewing directions).

In Fig. 11(b), the multiangular calibration results obtained for site Niger 2 are plotted. Even if this site was not among the sites characterized with in-situ data, the standard deviation of multiangular calibration results is lower than for Algeria, ranging from $2.3 \%$ in band 443 to $0.8 \%$ for 865 . The errors decrease when the wavelength increases, as do the directional effects of the desert site. Once again, the results indicate a good multiangular calibration for all spectral bands except 443 , but it is still difficult to conclude if it comes from the inaccuracy of the BRDF model in this band or from multiangular calibration.

As a conclusion, this multiangular calibration method confirms the quality of the preflight multiangular calibration and the temporal stability of the instrument, except for spectral band 443: in this case, multiangular calibration may have evolved after launch. But since confidence in $443 \mathrm{~nm}$ result is low, preflight calibration of this parameter is still used in the level 1 product. The BRDF's of the 20 desert sites are now being characterized using POLDER data in order to use it to cross calibrate POLDER with over optical sensors (Section V-C).

2) High-Frequency Multiangular Calibration over Clouds: Changes after launch in the high-frequency multiangular calibration of POLDER might occur for two reasons: i) if the elementary sensitivities of the detectors in the CCD array change because of temperature variation or because of airvacuum transition or ii) if particles of dust are deposited on the optics after the last preflight calibration, or if they move in the field-of view (POLDER pupil dimension is around $0.4 \mathrm{~mm}^{2}$ in the center of the external lens). However, the POLDER CCD array is thermally controlled and air vacuum transition was tested before launch without showing any significant variation: the first cause of variation is unlikely.

In order to determine this high-frequency multiangular in-flight calibration with an accuracy around $0.1 \%$, a new method has been developed using cloud observations. For each elementary detector of the CCD array, and for each channel, the method consists in averaging all the cloud observations performed by the detector. The procedure assumes that if a very high number of cloud observations is collected for each elementary detector, the high-frequency variations of the average of all the measurements will characterize the sensitivity variations within the array, and only the low frequencies will be affected by artifacts of cloud anisotropy.

This calibration method has been experimented with NOAA/AVHRR band 1 raw data using the fact that one line in an AVHRR product is obtained with a single detector. 30000 lines of AVHRR data have been used. The data have been processed as if each line was acquired with 2048 different detectors having exactly the same sensitivity. The observed high frequencies variations would then be only artifacts. AVHRR cloud detection is performed by a simple threshold on the normalized radiance $(I>0.25)$, since the procedure does not require a precise cloud mask. For each column number of AVHRR data, all the cloud measurements are averaged, and the standard deviation of the averages is computed: the obtained accuracy is under $0.3 \%$.

The same method has been used for POLDER. In this case, the only difficulty is related to the amount of data necessary for the calibration: the required number of cloud measurements is 15 (channels) $\times 66308$ (detectors) $\times 15000$ (measurements). This requires the use of three entire weeks of POLDER data (there are only 120 measurements per orbit for a given POLDER detector in one spectral band and only one half of them are clouds). In order to estimate the accuracy of the results, two sets of three weeks have been used to obtain two results with independent data sets. The difference between the results of the two data sets has a standard deviation around $0.2 \%$, which indicates that the results obtained from the whole six weeks of data have a precision better than $0.2 \%$. The difference between preflight and in-flight data is between $0.3 \%$ and $0.1 \%$, depending on the spectral bands. A few dust particle 

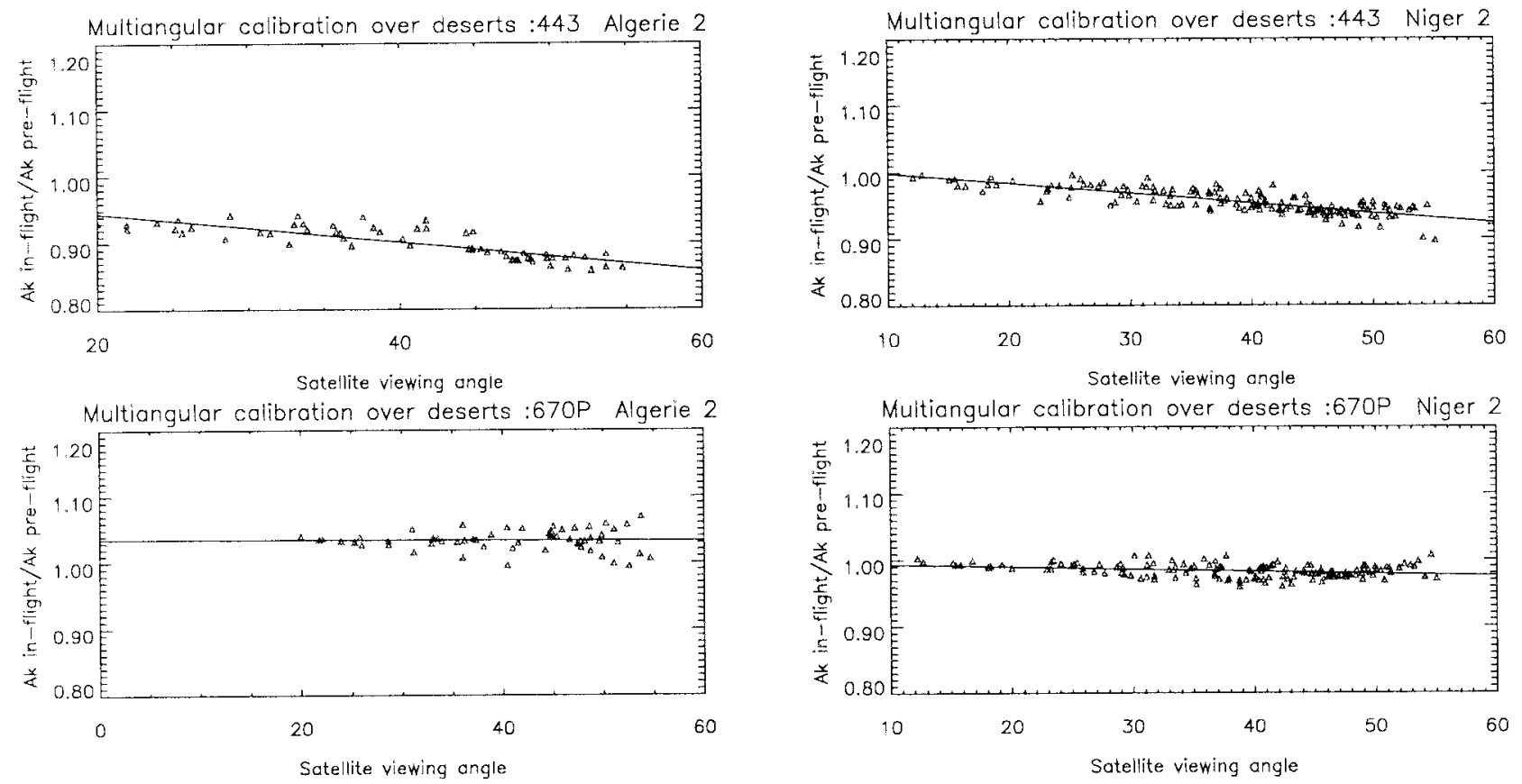

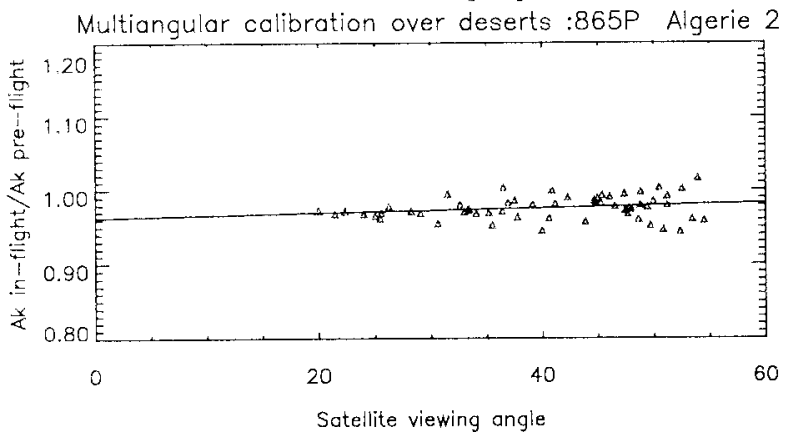

(a)

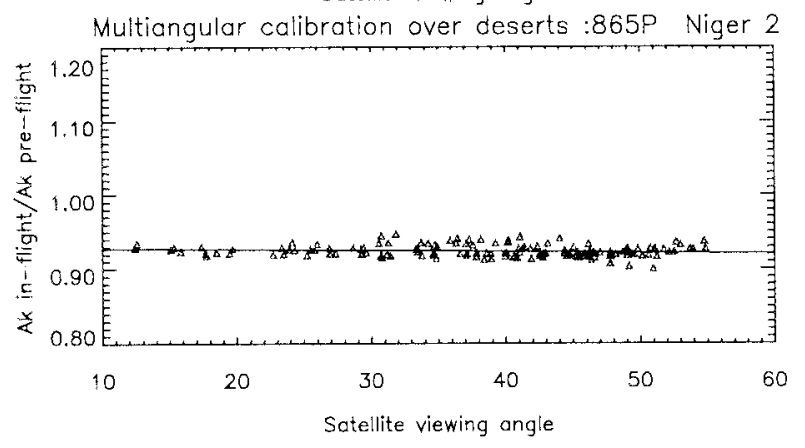

(b)

Fig. 11. Multiangular calibration of POLDER over desert sites as a function of satellite viewing angle $\theta$ : (a) Algeria 2 site: the number of cloud-free acquisitions during November, 1996, was low over this site, and dispersion of the results is rather high for the remaining points. A variation of POLDER multiangular calibration may be possible for $443 \mathrm{~nm}$ band. (b) Niger 2 site: the number of cloud-free acquisitions during November, 1996, was much higher than for Algeria 2, and the dispersion of the results is also lower, but the BRDF model was not measured on this site. A variation of POLDER multiangular calibration might be possible for 443-nm band, whereas the two other bands seem to be correctly calibrated.

effects have been noticed with differences of about $1 \%$, and some differences are linked to the disappearing of artifacts in the preflight calibration.

The coefficients determined by this method are now implemented in POLDER level 1 processing.

\section{In-FLIGHT RADIOMETRICAL CALIBRATION: VALIDATION}

In this chapter are presented three additional calibration methods that were used to validate the results of POLDER in-flight calibration nominal methods. These independent calibration methods are based on different atmospheric models or different calibration sources (including on-board sources for POLDER/ATSR2 cross calibration) in order to verify that the nominal methods are not biased.

\section{A. Interband Calibration Using Clouds}

Starting from level 1 data calibrated with the nominal methods, we use the 670-nm radiance measurements as a reference for the estimation of 443-nm and 490-nm absolute calibration coefficients (565 is usually saturated over high reflective clouds). The calibration pixels are selected when their reflectance is over 0.8 , when the cloud top apparent pressure deduced from the band ratio 763/765 [4] is under $250 \mathrm{hPa}$, and when the clouds are uniform enough. Data are corrected for ozone absorption using TOMS data.

Simulations of TOA radiances above convective clouds have been performed using a discrete ordinate method: they are arranged in look-up tables calculated for 443-, 490-, and 670-nm channels. They correspond to three different ice particles (hexagonal plates or columns with a radius 20-60 $\mu \mathrm{m}$, assumed to be dominant in the highest layers of cumulonimbus), to a cloud top altitude of 10 or $15 \mathrm{~km}$, to a dense grid of observation angles, and to scattering cloud optical thickness between 20 and 200 .

For a given altitude and ice particle model, the first step of the procedure finds the scattering optical thickness $\delta_{\text {est }}$ that corresponds to the observed radiance at $670 \mathrm{~nm}$. Then the 
LUT at 443 and 490 are used to estimate the radiances in these bands, assuming the cloud optical thickness does not vary between 443 and $670 \mathrm{~nm}$.

The new estimated calibration coefficient is obtained from the initial coefficient $A^{k}$ and from measured $M I^{k}$ and estimated radiance $C I^{k}\left(\delta_{\text {est }}\right)$ by

$$
A_{\mathrm{in}-\text { flight }}^{k}=A_{\text {preflight }}^{k} \times \frac{M I^{k}}{C I^{k}\left(\delta_{\text {est }}\right)} .
$$

The average results derived from 12 POLDER orbits in November 1996, are reported in Table V. The standard deviation is below $0.8 \%$ for the 443 and 490 channels. Changing the cloud top altitude from 15 to $10 \mathrm{~km}$ results in an increase of $1 \%$ in the calibration coefficient, and the choice of the particle model does not introduce more than $0.5 \%$ of variation. The results do not depend on the cloud reflectance, meaning that the selected clouds are thick enough so that the radiance of the surface and of the atmospheric layer below the cloud does not impact on the calibration. The interband calibration results over clouds do not agree perfectly with the results obtained with the nominal methods: the discrepancy at $443 \mathrm{~nm}$ is about $6 \%$ (only $3 \%$ at 490 ) and has still not been explained in spite of comprehensive verifications.

\section{B. Cross Calibration Between POLDER and OCTS}

OCTS is a NASDA radiometer which flew on board ADEOS. Its nadir resolution is around $800 \mathrm{~m}$, the swath is $1400 \mathrm{~km}$ wide, and acquisitions are made with eight visible and near infrared bands and four thermal infrared bands. OCTS scanning mechanism is based on a rotating mirror with a maximum scanning angle of $40^{\circ}$, and ten detectors per spectral band are used to collect simultaneously ten lines across-track. Since POLDER and OCTS are on the same platform and share six spectral bands $(443,490,565,670$, 765 , and 865), it is possible to compare the radiance of targets observed at the same instant with the same viewing and solar angles and in nearly identical spectral bands. Simultaneous acquisitions of POLDER and OCTS data have been used in order to cross calibrate both sensors.

In order to enhance the accuracy of the cross calibration, the targets are chosen so that they have a quite high normalized radiance (more than 0.2 ), a very low polarization rate (polarization sensitivity is not corrected for OCTS), and a good spatial uniformity to avoid possible registration errors between the two sensors: a POLDER pixel is used for cross calibration if the standard deviation of the OCTS measurements inside it is less than $1 \%$ of the radiance. The targets corresponding to these criteria are mostly clouds, which also have the advantage of being quite spectrally flat.

Table $\mathrm{V}$ gives the absolute calibration derived considering OCTS preflight calibration as a reference (this preflight calibration was still used in the OCTS level 1B products with software ID 3 7). Agreement with the POLDER in-flight method stays within a 7\% margin. The same computation has been made using the in-flight calibration of OCTS that is used to produce the version 3.0 ocean color products. This calibration is in fact called "algorithm tuning parameters" by

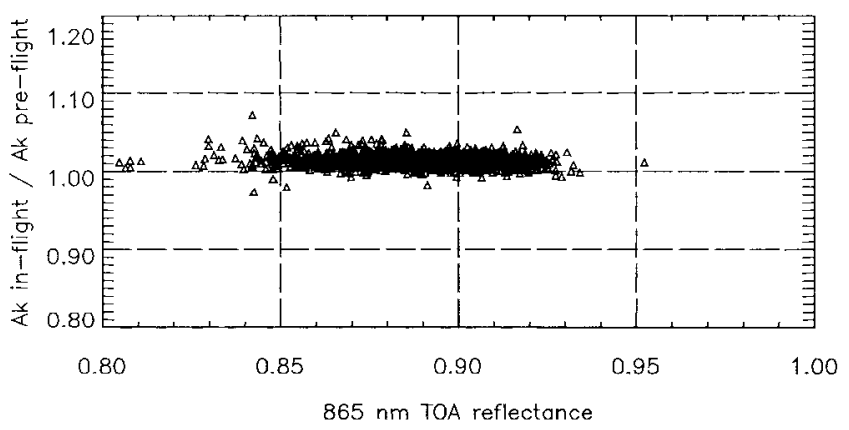

Fig. 12. Absolute calibration elementary results for clouds interband method as a function of the cloud $865-\mathrm{nm}$ reflectance. The interband calibration over clouds is $443 \mathrm{~nm}$.

the OCTS calibration team: it was obtained for all spectral bands by comparing in-situ chlorophyll-a data with OCTS data [26], and its aim was not to perfectly calibrate OCTS data but to obtain the best ocean color products. One can note that the agreement is good for 443 and 490 and gets worse as the wavelength increases ( $22 \%$ for $865 \mathrm{~nm}$ band). This can probably be explained by OCTS in-flight calibration of 865$\mathrm{nm}$ band with a Rayleigh method that uses very low radiances in the near-infrared bands over ocean.

\section{Cross Calibration Between POLDER and ATSR2}

ATSR-2 is a multispectral scanner on board the ERS-2 satellite launched in 1995. It is based on a conical scanning mechanism which allows the acquisition of the same scenes from two viewing angles during a single pass: a forward along track view (viewing zenith angle around $60^{\circ}$ ) and a nadir view. ATSR-2 has four infrared channels and three visible/nearinfrared channels very close to POLDER spectral bands: 560, 660 , and $870 \mathrm{~nm}$. ATSR-2 is calibrated using an on-board diffuser monitored by a photodiode, and using desert sites to measure the drift of the on-board calibration system [34]. A successful cross-calibration between both instruments would be a good validation of both sensor's absolute calibration and also a partial validation of POLDER multiangular calibration.

Since POLDER and ATSR-2 acquisitions of the same scenes are not simultaneous, the cross calibration target must be stable with time, uniform to avoid geometrical registration problems, and its BRDF has to be known: the desert site Sudan 1 has been used for this cross calibration. Thanks to its bidirectional capabilities, POLDER is able to obtain a dense sampling of the viewing conditions over one site. Each month, a BRDF model of the desert site is derived from all the cloud-free measurements obtained by POLDER. Each available cloudfree ATSR2 measurement is then compared to the interpolation of the BRDF model of the same month for ATSR2 viewing conditions. Cloud detection for POLDER data is described in Section IV-B, and for ATSR-2 in Smith et al. [32]. POLDER data are corrected for gaseous absorption as described in the Appendix and ATSR-2 data are corrected for ozone absorption using TOMS data. Of course, aerosols above the desert site can cause some variability in the results, but by accumulating enough data, the results should not be biased. 


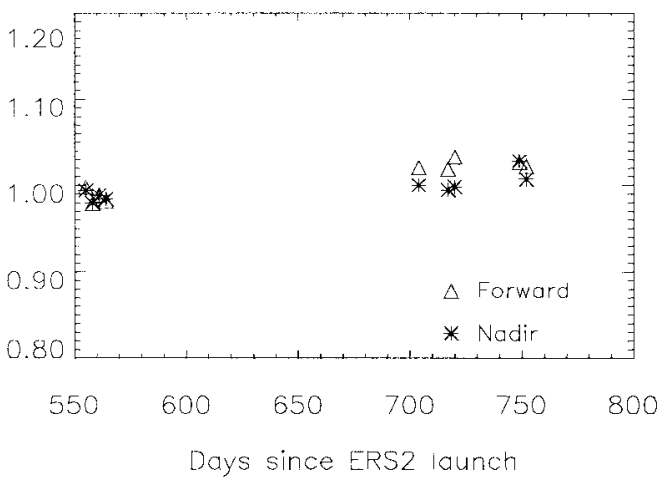

Fig. 13. Ratio of the reflectances at $670 \mathrm{~nm}$ measured by ATSR2 and POLDER over a desert site (Sudan 1) from November 1996 to May 1997 with the same viewing angles. Stars indicate that the data have been acquired with nadir viewing, whereas triangles correspond to a forward viewing. In most of the cases, triangles and stars overlap when acquired the same day, and this provides a validation of POLDER multiangular calibration.

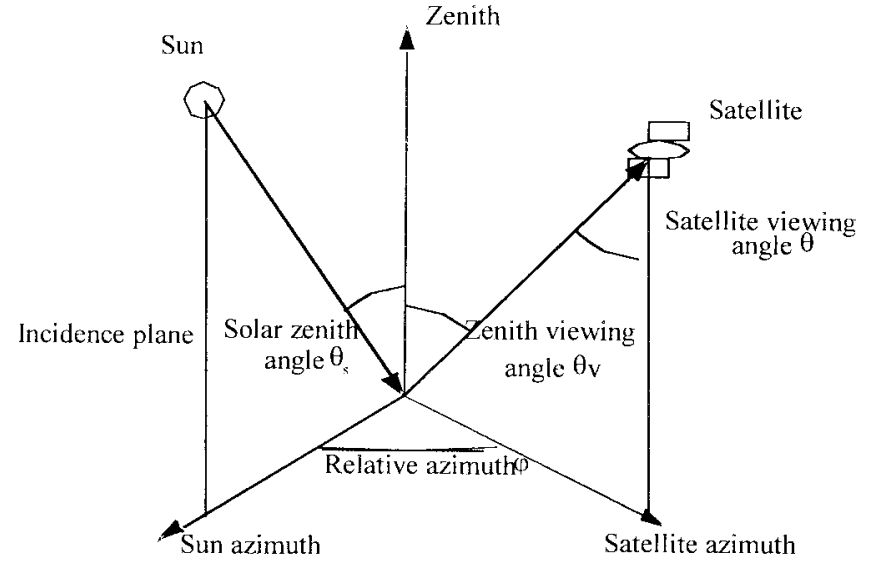

Fig. 14. Definition of the various angles used to characterize the geometry of satellite acquisitions.

The results are quite good (Table V): the agreement between the radiance measured by ATSR-2 and the BRDF derived from POLDER is better than $6 \%$ for $565,1 \%$ for 670 , but degrades to $5 \%$ for 865 . The agreement between the directional variations of POLDER BRDF and ATSR-2 reflectances is also very satisfactory and validates partially POLDER multiangular calibration in these spectral bands (Fig. 13).

\section{CONCLUSION}

A new calibration approach has been developed for POLDER based on the design of a very stable instrument, on an exhaustive preflight calibration of the instrument, and on the development of many in-flight operational calibration methods using natural targets. The result is very satisfactory since the in-flight absolute calibration has shown that:

- POLDER Instrument is Stable: All in-flight absolute calibration coefficients differ from preflight coefficients by less than 5\%, and multiangular calibration did not evolve after launch (except maybe for 443);

- in-flight calibration methods (except POLDER/OCTS cross calibration) agree within a margin of $4 \%$ for all the spectral bands but 443 .
This calibration process is efficient to provide a correct absolute calibration within a few months (five months were necessary for POLDER 1, but this delay will be reduced with POLDER 2). It is less expensive than developing an on-board calibration device, and more reliable than using insitu measurement campaigns which are subject to weather conditions and provide very few calibration points, maximizing the impact of random error sources. However, all these methods are perfectly suited to POLDER measurements and could not be easily applied to other instruments that do not provide multidirectional measurements (for aerosol detection in sunglint calibration method) or $\mathrm{O}_{2}$ pressure (for cloud altitude determination in interband calibration using clouds). Such accuracy also could not be achieved without a good characterization and correction of POLDER polarization sensitivity, since our calibration targets (Rayleigh scattering and sunglint) have a high polarization rate.

Still, some uncertainty exists in the calibration of the 443$\mathrm{nm}$ channels, with a discrepancy of $6 \%$ between the Rayleigh and the cloud methods that has not yet been explained in spite of intensive verifications.

\section{APPENDIX \\ CORRECTIONS FOR GASEOUS ABSORPTION}

Ozone absorption is removed by computing the transmissions $T_{\mathrm{O}_{3}}^{k}$ as functions of $m \cdot U_{\mathrm{O}_{3}}$, where $m$ is the air mass factor and $U_{\mathrm{O}_{3}}$ is the column amount of ozone measured by TOMS. The water vapor transmission $T_{\mathrm{H}_{2} \mathrm{O}}^{k}$ is modeled as a function of the ratio of 910- and 865-nm normalized radiances $\left(M I^{910} / M I^{865}\right)$. The parameterizations of ozone and water vapor transmissions are derived from simulations using a line-by-line model.

For the oxygen absorption in the 763 and 765 spectral bands, the normalized radiance $M I^{*}$ that would be measured if there was no absorption is assumed to be the same in both channels (which is really true for sunglint targets). The normalized radiances measured by POLDER $\left(M I^{763}\right.$ and $\left.M I^{765}\right)$ can be expressed as a function of $M I^{*}$ as follows:

$$
M I^{763}=M I^{*} \cdot T_{\mathrm{O}_{2}}^{763} \cdot T_{\mathrm{H}_{2} \mathrm{O}}^{763} \cdot T_{\mathrm{O}_{3}}^{763}
$$

$$
M I^{765}=A \cdot M I^{763}+(1-A) \cdot M I^{*} \cdot T_{\mathrm{H}_{2} \mathrm{O}}^{765} \cdot T_{\mathrm{O}_{3}}^{765}
$$

In this formula, the constant $A$ may be considered as the percentage of the 765 spectral band where oxygen lines are located. Its value is derived from line-by-line simulations and is close to 0.3 . The oxygen transmittance $T_{\mathrm{O}_{2}}^{763}$ and the normalized radiance without absorption $\mathrm{MI}^{*}$ can be derived by combining (A1) and (A2).

\section{ACKNOWLEDGMENT}

The authors are grateful to H. Oaku (NASDA/EORC) for supplying OCTS data, to D. L. Smith in the Rutherford Appleton Laboratory, U.K. for providing ATSR-2 extractions over site Sudan1, and to all the persons in CNES who helped 
the authors exploiting the huge amount of POLDER data used to provide the above results: C. Gélis, P. Théron, A. Meygret, P. Soulé, J. M. Laherrére, A. Guerry, and S. Lafont.

\section{REFERENCES}

[1] Y. Andre, J. M. Laherrere, T. Bret-Dibat, M. Jouret, J. M. Martinuzzi, and J. Perbos, "Instrumental concept and performances of the POLDER instrument," in SPIE Proc. Infrared Spaceborne Remote Sensing III, San Diego, CA, July 1995, vol. 2553.

[2] S. Bouffiès, D. Tanré, F. M. Bréon, and P. Dubuisson, "Atmospheric water vapor estimate by a differential absorption technique with the POLDER instrument," J. Geophys. Res., vol. 102, pp. 3831-3841, 1997.

[3] T. Bret-Dibat, Y. André, and J. M. Laherrere, "Preflight calibration of the POLDER instrument," in SPIE Proc. Remote Sensing and Reconstruction for Three Dimensional Objects and Scenes, San Diego, CA, July 1995, vol. 2572 .

[4] J. C. Buriez, C. Vanbauce, F. Parol, P. Goloub, M. Herman, B. Bonnel, Y. Fouquart, P. Couvert, and G. Sèze, "Cloud detection and derivation of cloud properties from POLDER," Int. J. Remote Sens., vol. 18, no. 13, pp. 2785-2813, 1997.

[5] F. Cabot, G. Dedieu, and P. Maisongrande, "Monitoring NOAA/AVHRR and Meteosat shortwave bands and calibration over stable areas," in Proc. 6th ISPRS Int. Symp. Physics, "Measurements and signatures in remote sensing," Val d'Isére, France, Jan. 17-21, 1994, pp. 41-46.

[6] H. Cosnefroy, M. Leroy, and X. Briottet, "Selection and characterization of Saharan and Arabian desert sites for the calibration of optical satellite sensors," Remote Sens. Environ., vol. 58, no. 1, pp. 101-114, 1996.

[7] H. Cosnefroy, X. Briottet, M. Leroy, P. Lecomte, and R. Santer, "A field experiment in Sahara for the calibration of optical satellite sensors," Int. J. Remote Sens., vol. 18, no. 16, pp. 3337-3359, 1997.

[8] C. Cox and W. Munk, "Slopes of the sea surface deduced from photographs of sun glitter," Bull. Scripps Inst. Ocean., vol. 6, pp. 401-488, 1985 .

[9] P.-Y. Deschamps, F. M. Bréon, M. Leroy, A. Podaire, A. Bricaud, J. C Buriez, and G. Sèze, "The POLDER mission: Instrument characteristics and scientific objectives," IEEE Trans. Geosci. Remote Sensing, vol. 32, pp. 598-615, 1994

[10] J.-L. Deuzé, M. Herman, and R. Santer, "Fourier series expansion of the transfer equation in the atmosphere ocean system," J. Quant. Spectrosc. Radiat. Transfer, vol. 41, pp. 483-494, 1989.

[11] B. Fougnie, P.-Y. Deschamps, and R. Frouin, "Vicarious calibration of the POLDER ocean color spectral bands using in situ measurements," IEEE Trans. Geosci. Remote Sensing, this issue, pp. 1567-1574.

[12] B. Fougnie and P. Y. Deschamps, "Observation et modélization de la signature spectrale de l'écume de mer," in Proc. 7th Int. Colloq. Physical Measurements and Signatures in Remote Sensing, Apr. 7 and 11, 1997, pp. 227-234.

[13] P. Goloub, B. Toubbe, M. Herman, T. Bailleul, O. Hagolle, J. M. Martinuzzi, and B. Rougé, "In-flight polarization calibration of POLDER," in Proc. EUROPTO Advanced and Next-Generation Satellites, 1996, vol. 2957, pp. 299-310.

[14] H.-R. Gordon and M. Wang, "Retrieval of water leaving radiance and aerosol optical thickness over the oceans with Seawifs: A preliminary algorithm," Appl. Opt., vol. 33, pp. 443-452, 1994.

[15] O. Hagolle, A. Guerry, L. Cunin, B. Millet, J. Perbos, J.-M. Laherrere, T. Bret-Dibat, and L. Poutier, "POLDER Level 1 processing algorithms," in SPIE Aerosense Proc. Algorithms for Multispectral and Hyperspectral Imagery II, Orlando, FL, 1996, pp. 308-319.

[16] O. Hagolle, A. Guerry, L. Cunin, B. Millet, J. Perbos, J.-M. Laherrere, and T. Bret-Dibat, "POLDER level 1 processing algorithms," SPIE Proc., vol. 2758, pp. 308-319, 1996.

[17] P. Henry, M. Dinguirard, and M. Bodilis, "Spot multitemporal calibration over stable desert areas," in SPIE Int. Symp. Aerospace and Remote Sensing, Tech. Conf. 1938, Orlando, FL, Apr. 12-16, 1993, pp. 67-76.

[18] B.-N. Holben, Y.-J. Kaufman, and J.-D. Kendall, "NOAA_11 AVHRR visible and near-infrared in-flight calibration," Int. J. Remote Sens., vol. 11, pp. 1511-1519, 1990.

[19] P. Koepke, "Effective reflectance of oceanic white caps," Appl. Opt., vol. 20, p. 34, 1984.

[20] J. M. Laherrere, L. Poutier, T. Bret-Dibat, O. Hagolle, C. Baqué, P. Moyer, and E. Verges, "POLDER on-ground stray light analysis, calibration and correction," EUROPTO SPIE Proc., vol. 3221, pp. $132-140$.

[21] A. Lifermann, J.-L. Counil, J.-M. Martinuzzi, and J. Perbos, "General outlines of the POLDER experiment," in SPIE Proc. Symp. Satellite Remote Sensing II, Paris, France, Sept. 1995, pp. 245-252.
[22] A. Meygret, O. Hagolle, P. Henry, M. Dinguirard, P. Hazane, R. Santer, and J.-L. Deuzé, "SPOT 3: First in-flight calibration results," in Proc: IGARSS'94, Pasadena, CA, 1994.

[23] A. Morel, "Optical modeling of the upper ocean in relation to its biogenous matter content (case I waters)," J. Geophys. Res., vol. 93, no. C9, pp. 10749-10768, Sept. 15, 1988.

[24] C. Moulin, C. E. Lambert, J. Poitou, and F. Dulac, "Long term (1983-1994) calibration of the Meteosat solar (VIS) channel using desert and ocean targets," Int. J. Remote Sens., vol. 17, no. 6, pp. 1183-1200, 1996.

[25] A.-P. McNally and M. Vesperini, "Variational analysis of humidity information from TOVS radiances," EUMETSAT/ECMWF Res. Rep. 1

[26] OCTS Team: M. Shimada et al., "A CAL/VAL report on the OCTS Version 3 products," Feb. 98, NASDA Intern. Rep.

[27] R. M. Pope and E. S. Fry, "Absorption spectrum (380-700nm) of pure water-II: Integrating cavity measurements," Appl. Opt., vol. 36, no. 33, p. 8710,1997

[28] L.-S. Rothman, C.-P. Rinsland, A. Goldman, S.-T. Massie, D.-P. Edwards, J.-M. Flaud, A. Perrin, C. Camy-Peyret, V. Dana, J.-Y. Mandin, J. Schroeder, A. McCann, R.-R. Gamache, R.-B. Wattson, K. Yoshino, K. Chance, K. Jucks, L.-R. Brown, V. Nemtchinov, and P. Varanasi, "The HITRAN molecular spectroscopic database and HAWKS (HITRAN Atmospheric Workstation): 1996 Edition," J. Quant. Sprectrosc. Radiat. Transfer, 1998.

[29] F. Sakuma, T. Bret-Dibat, H. Sakate, A. Ono, J. Perbos, J. M. Martinuzzi, K. Imaoka, H. Oaku, T. Moriyama, Y. Miyachi, and Y. Tange, "POLDER-OCTS preflight cross calibration using round robin radiometers," in SPIE Proc. Infrared Spaceborne Remote Sensing III, San Diego, CA, July 1995, vol. 2553.

[30] R. Santer, M. Asmani, E. Vermote, and M. Sharman, "In-flight calibration of channels 1 and 2 of AVHRR using desertic sites and clouds," in Proc. 5th ISPRS Int. Symp. Physics on Measurements and Signatures in Remote Sensing, Courchevel, France, 1991, pp. 65-68.

[31] M. Schwindling, P.-Y. Deschamps, and R. Frouin, "Verification of aerosol models for satellite ocean color remote sensing," J. Geophys. Res., pp. 24919-24935, 1998.

[32] E. Shettle and R. Fenn, "Models for the aerosols of the lower atmosphere and the effects of humidity variations on their optical properties," AGFL-TR-79-0214, Sept. 20, 1979.

[33] P.-N. Slater, S.-F. Biggar, K.-J. Thome, D.-I. Gellman, and P.-R. Spyak, "Vicarious radiometric calibrations of EOS sensors," Amer. Meteorol. Soc. J., 1996.

[34] D.-L. Smith, P.-D. Read, and C.-T. Mutlow, "The calibration of the visible/near infra-red channels of the along-track-scanning-radiometer-2 (ATSR2)," in EUROPTO Proc. Sensors, Systems, and Next Generation Satellites, London, Brittany, Sept. 97, vol. 3221, pp. 53-62.

[35] K. Stamnes, S. C. Tsay, W. Wiscombe, and K. Jayaweera, "Numerically stable algorithm for discrete ordinate method radiative transfer in multiple scattering and emitting layered media," Appl. Opt., vol. 12 pp. 2502-2509, 1998.

[36] W. F. Staylor, "Degradation rates of the AVHRR visible channel for the 6, 7 and 9 spacecraft," J. Atmos. Ocean. Technol., vol. 7, pp. 411-423, 1990.

[37] C. Vanbauce, J.-C. Buriez, F. Parol, B. Bonnel, G. Sèze, and P. Couvert, "Apparent pressure derived from ADEOS-POLDER observations in the oxygen A-band over ocean," Geophys. Res. Lett., 1998

[38] E. Vermote and Y.-J. Kaufman, "Absolute calibration of AVHRR visible and near infrared using ocean and cloud views," Int. J. Remote Sensing, vol. 16 , no. 13 , pp. 2317-2340, 1995.

[39] E. Vermote, R. Santer, P. Y. Deschamps, and M. Herman, "In-flight calibration of large field of view sensors at short wavelengths using Rayleigh scattering," Int. J. Remote Sensing, vol. 13, no. 18, pp. 3409-3429.

[40] E. Vermote, D. Tanré, J. L. Deuzé, M. Herman, and J. J. Morcrette, "Second simulation of the satellite signal in the solar spectrum, 6S: An overview," IEEE Trans. Geosci. Remote Sensing, vol. 35, pp. 675-685, May 1997.

[41] M. Vesperini, F. M. Breon, and D. Tanré, "Atmospheric water vapor content from POLDER spaceborne measurements," this issue, pp. $1613-1619$.

[42] C. Wehrli, "Extraterrestrial solar spectrum," Publ. no. 615 PhysikalischMeteorologishes Observatorium, World Radiation Center, Davosdorf, Switzerland, 1985

[43] B. Toubbé, T. Bailleul, J. L. Deuzé, Ph. Goloub, O. Hagolle, and M Herman, "In flight calibration of the POLDER instrument using the sun's glitter," IEEE Trans. Geosci. Remote Sensing, vol. 37, pp. 513-525, Jan. 1999. 
Olivier Hagolle, for a photograph and biography, see p. 525 of the January 1999 issue of this TRANSACTIONS.

Philippe Goloub, for a photograph and biography, see p. 525 of the January 1999 issue of this TRANSACTIONS.

Pierre-Yves Deschamps received the Ph.D. degree in 1977 in atmospheric physics from the Université de Lille, France.

Since then, he has been a Researcher at the Centre National de la Recherche Scientfique, working at the Laboratoire d'Etudes et de Recherches en Télédétection Spatiale and at the Laboratoire d'Optique Atmosphérique. He conducts research in atmospheric satellite remote techniques to retrieve various biophysical parameters for use in climate change studies.

Hélène Cosnefroy, photograph and biography not available at the time of publication.

Xavier Briottet received the $\mathrm{Ph} . \mathrm{D}$. degree in electronics from Ecole National Supérieure de l'Aéronautique et de l'Espace, Toulouse, France, in 1986.

Since 1986, his primary research interest in the remote sensing domain are in vicarious calibration using Rayleigh scattering and desert sites and in multiresolution problems.

Thierry Bailleul, for a photograph and biography, see p. 525 of the January 1999 issue of this TRANSACTIONS.
Jean-Marc Nicolas graduated from the Institut National des Telecommunications in 1992.

He has been working at the Laboratoire d'Optique Atmospherique, Lille, France, since 1994, where he began to participate in the POLDER experiment as a Computer Scientist. He is interested in both atmospheric correction over ocean and calibration/validation activities for POLDER.

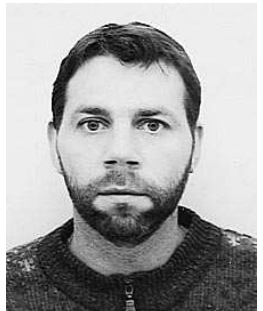

Frédéric Parol was born in 1963. He studied at the University of Lille, France, and received the M.S degree in physics in 1986 and the Ph.D. degree in atmospheric physics in 1990.

He is currently an Assistant Professor of physics at the University of Lille and a Researcher employed at the Laboratoire d'Optique Atmosphérique, Lille, France. He participated in the development of the first POLDER "Earth Radiation Budget and Clouds" processing line and he was especially in charge of the "Molecular absorption correction" and "Cloud pressure" algorithms. He has been a member of the International POLDER Science Working Team (IPSWT) since 1994. His work covers theoretical and experimental research in atmospheric science, radiative transfer, and remote sensing. His major areas of activity concern remote sensing of cloud properties, interaction between clouds and radiation, and the influence of clouds on climate.

Bruno Lafrance received the Ph.D. degree in atmospheric physics from the Université des Sciences et Technologies de Lille, Laboratoire d'Optique Atmosphérique, Lille, France, in 1997. His dissertation focused on the stratospheric aerosol correction for the POLDER data processing and the formation of polarized light in the atmosphere.

$\mathrm{He}$ is currently with the Center National d'Etudes Spatiales, Toulouse, France. He works on the interband calibration of POLDER and vegetation over thick clouds.

Maurice Herman, for a photograph and biography, see p. 525 of the January 1999 issue of this TRANSACTIONS. 